Revue des patrimoines

\title{
De la théorie au modèle : les hélices comme sculptures calculées, le cas des Fonderies de l'Atlantique à Nantes
}

Jean-Louis Kerouanton

\section{OpenEdition}

Journals

Édition électronique

URL : http://journals.openedition.org/insitu/4266

DOI : $10.4000 /$ insitu.4266

ISSN : 1630-7305

Éditeur

Ministère de la culture

Référence électronique

Jean-Louis Kerouanton, « De la théorie au modèle : les hélices comme sculptures calculées, le cas des Fonderies de l'Atlantique à Nantes », In Situ [En ligne], 10 | 2009, mis en ligne le 19 mai 2009, consulté le 19 avril 2019. URL : http://journals.openedition.org/insitu/4266 ; DOI : 10.4000/insitu.4266

Ce document a été généré automatiquement le 19 avril 2019

\section{(c) (i) () $\Theta$}

In Situ Revues des patrimoines est mis à disposition selon les termes de la licence Creative Commons Attribution - Pas d'Utilisation Commerciale - Pas de Modification 4.0 International. 


\title{
De la théorie au modèle : les hélices comme sculptures calculées, le cas des Fonderies de l'Atlantique à Nantes
}

\author{
Jean-Louis Kerouanton
}

Cet article a pour origine une découverte "sensible »: lors des travaux de l'Inventaire général en Pays de la Loire, il nous a été donné en 2001 d'établir un dossier documentaire sur l'usine Atlantic Industrie qui s'apprêtait à déménager du centre de Nantes pour s'installer en périphérie, un peu en aval le long de la Loire, dans les anciens bâtiments de la centrale électrique de Chantenay. L'opération a eu lieu entre 2001 et 2002. Elle a fait à l'époque l'objet d'une sensibilisation suffisante des acteurs pour arrêter partiellement les procédures de démolition de l'usine elle-même, tandis que la quasi-totalité des modèles de fonderie, pour la plupart en bois, était sauvegardée et déménagée. Parce qu'il s'intégrait au projet global de développement et de valorisation de l'île de Nantes, j'avais pu alors convaincre la Mission Île de Nantes de l'intérêt de cet ensemble; elle accepta d'établir une mission supplémentaire d'étude des objets en vue de leur sauvegarde ${ }^{1}$ tandis que démonstration fut faite rapidement auprès de la maîtrise d'œuvre que la démolition totale n'était pas indispensable. Bien au contraire, ces fours de la fin des années 1930 (fig. $\mathbf{n}^{\circ} \mathbf{1}, \mathbf{n}^{\circ}$ 2) qui s'avèrent exceptionnels, les fosses de coulée, une partie de la charpente métallique et le pont roulant monumental forment un ensemble digne de considération, tout à fait cohérent avec l'ensemble des traces industrielles existant sur l'île². 
Figure 1

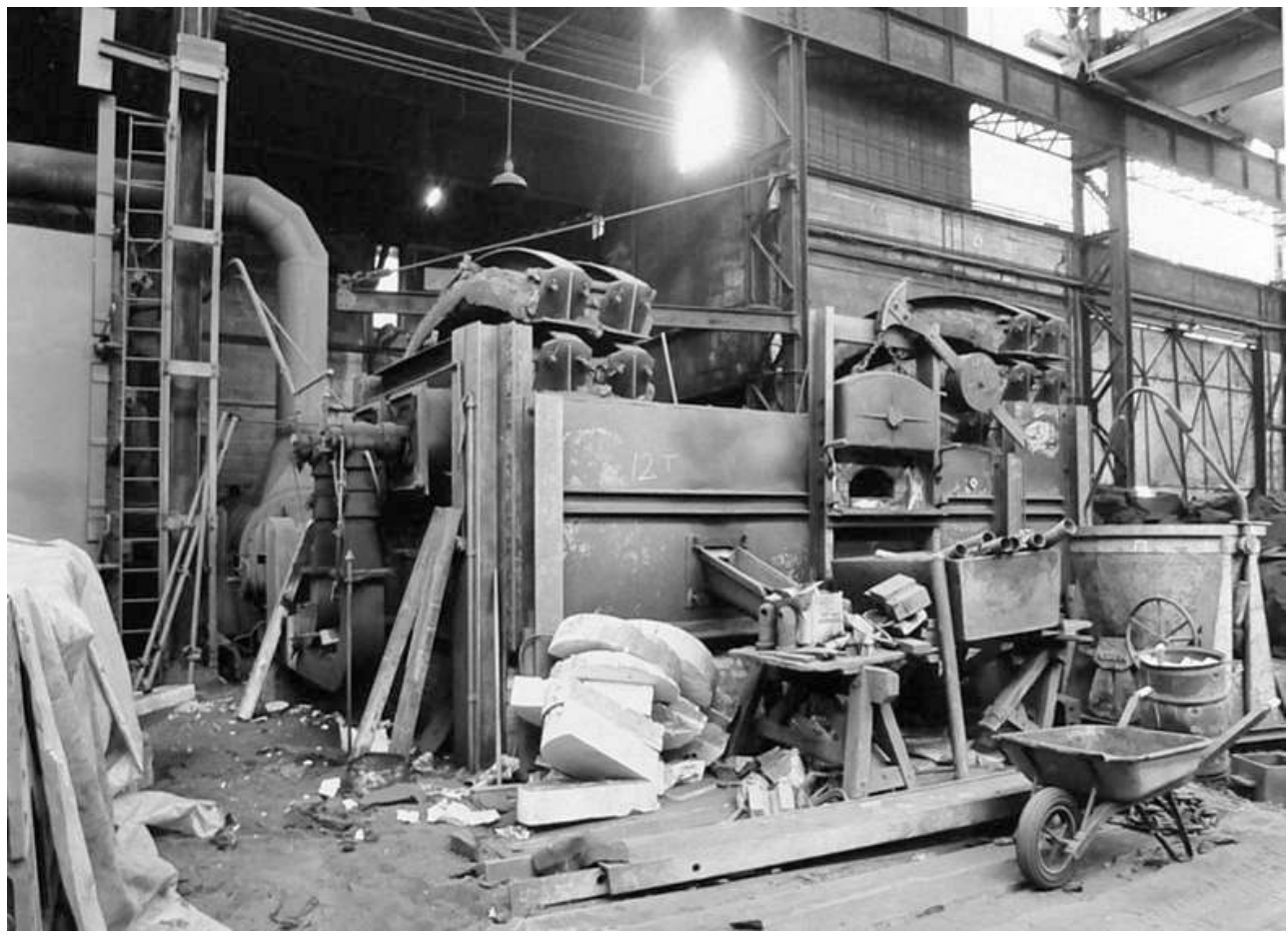

L'usine en fonctionnement, le four de 12 t. vu en 2001. Photo inventaire François Lasa.

(c) Région Pays de la Loire, Inventaire général.

Figure 2

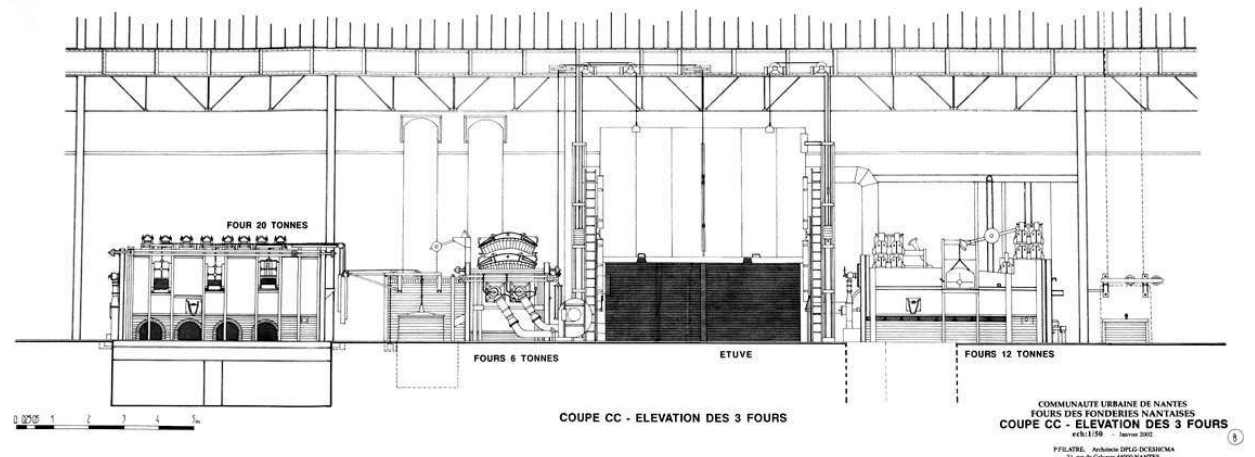

Relevé des fours en janvier 2002, avant démolition partielle des bâtiments, Élévation des trois fours, Pascal Filâtre, architecte, pour la Mission Île de Nantes.

(c) Communauté urbaine de Nantes.

2 Alexandre Chemetoff, architecte paysagiste, responsable de la maîtrise d'œuvre pour l'aménagement des espaces publics, comprit immédiatement l'intérêt du site et imagina un jardin autour des ruines, dont l'achèvement est prévu pour le printemps $2009^{3}$ (fig. $\mathbf{n}$ $-3,4,5)$. Pour des raisons politiques et économiques, les bâtiments industriels du boulevard Vincent-Gâche appartenaient déjà à la Ville de Nantes. Le déménagement et le maintien sur place des collections ont pu se faire par un simple transfert, la propriété pure et simple des objets restant encore sur place étant naturellement dévolue à l'acquéreur. Les bâtiments avaient été rachetés au cours d'une des périodes les plus 
difficiles de l'activité industrielle, afin de maintenir l'outil industriel sur place. Les repreneurs successifs n'étaient depuis que locataires des murs.

Figure 3

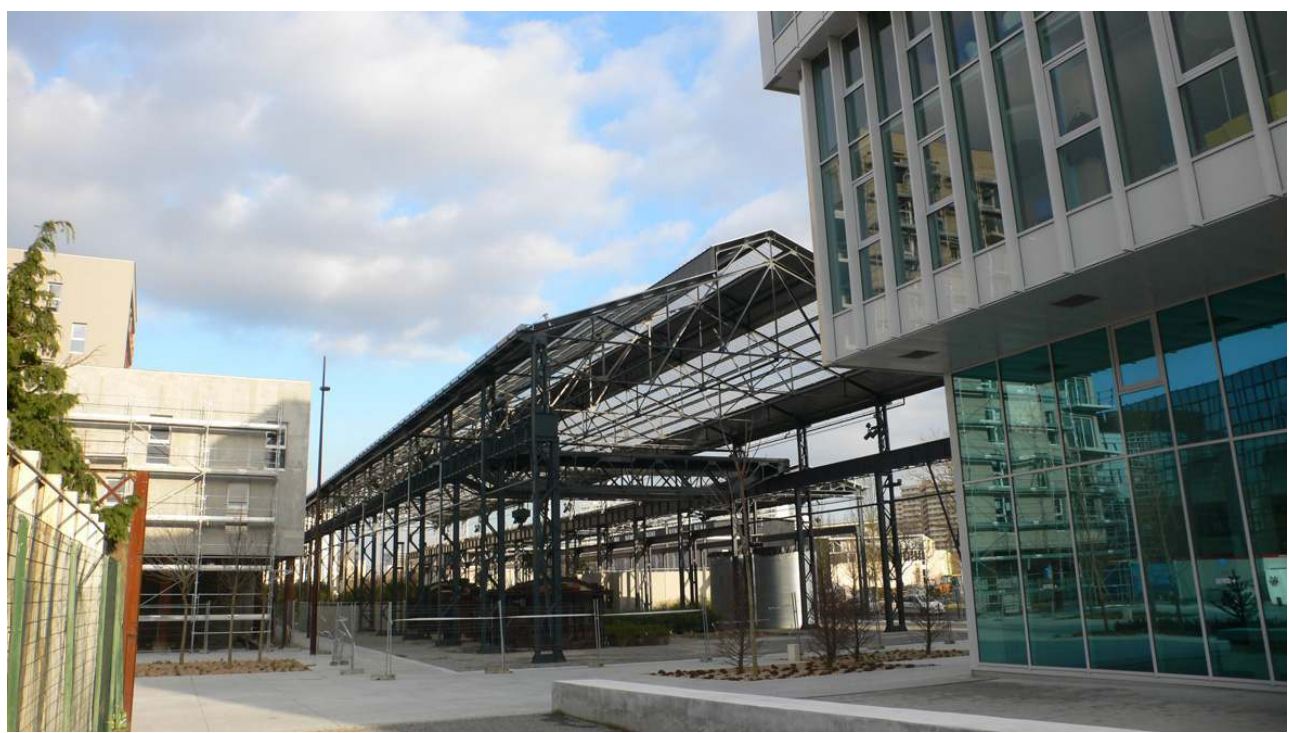

Conservation et réhabilitation de la nef de 1937 et réalisation d'un jardin d'hiver en 2009, Doazoan et Hirchsberger paysagistes. Vue d'ensemble vers l'est. Photo Jean-Louis Kerouanton, mars 2009.

(c) Jean-Louis Kerouanton.

\section{Figure 4}

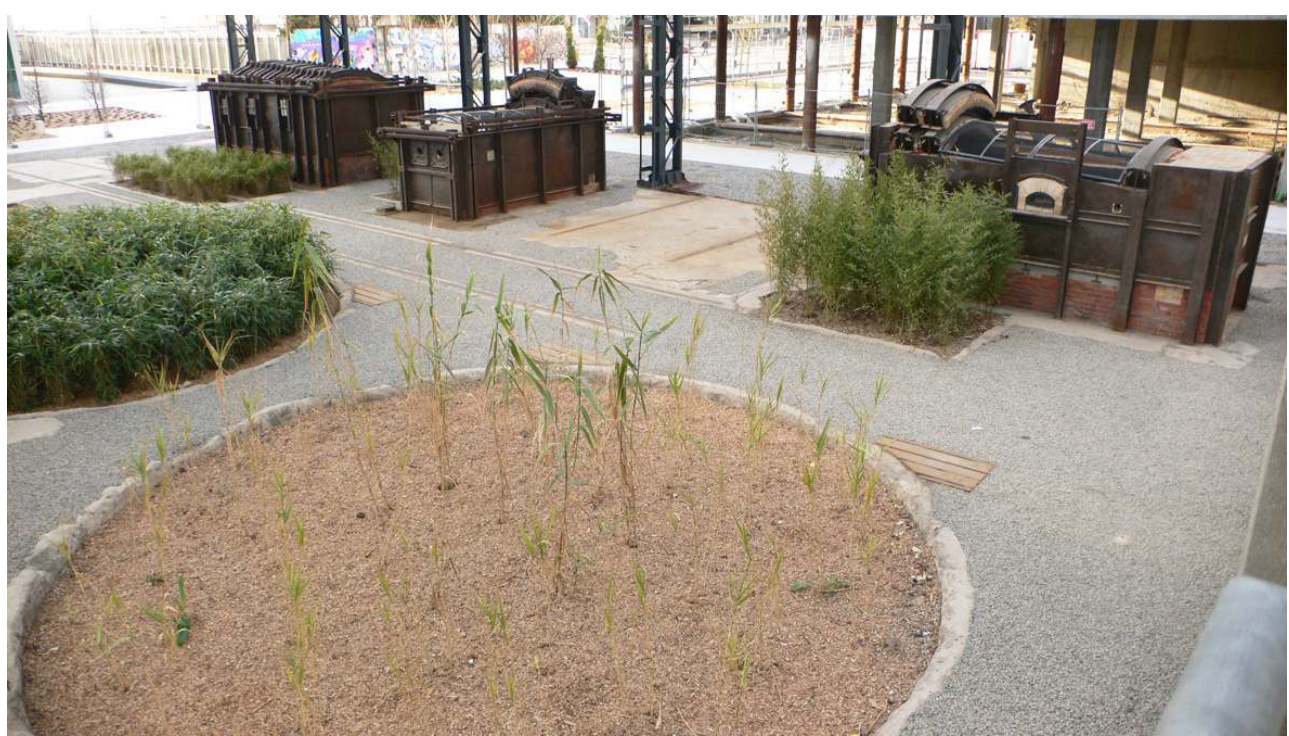

Conservation et réhabilitation de la nef de 1937 et réalisation d'un jardin d'hiver en 2009, Doazoan et Hirchsberger paysagistes. Les grandes fosses de coulée aménagées en jardin devant les fours restaurés. Photo Jean-Louis Kerouanton, mars 2009.

(c) Jean-Louis Kerouanton. 


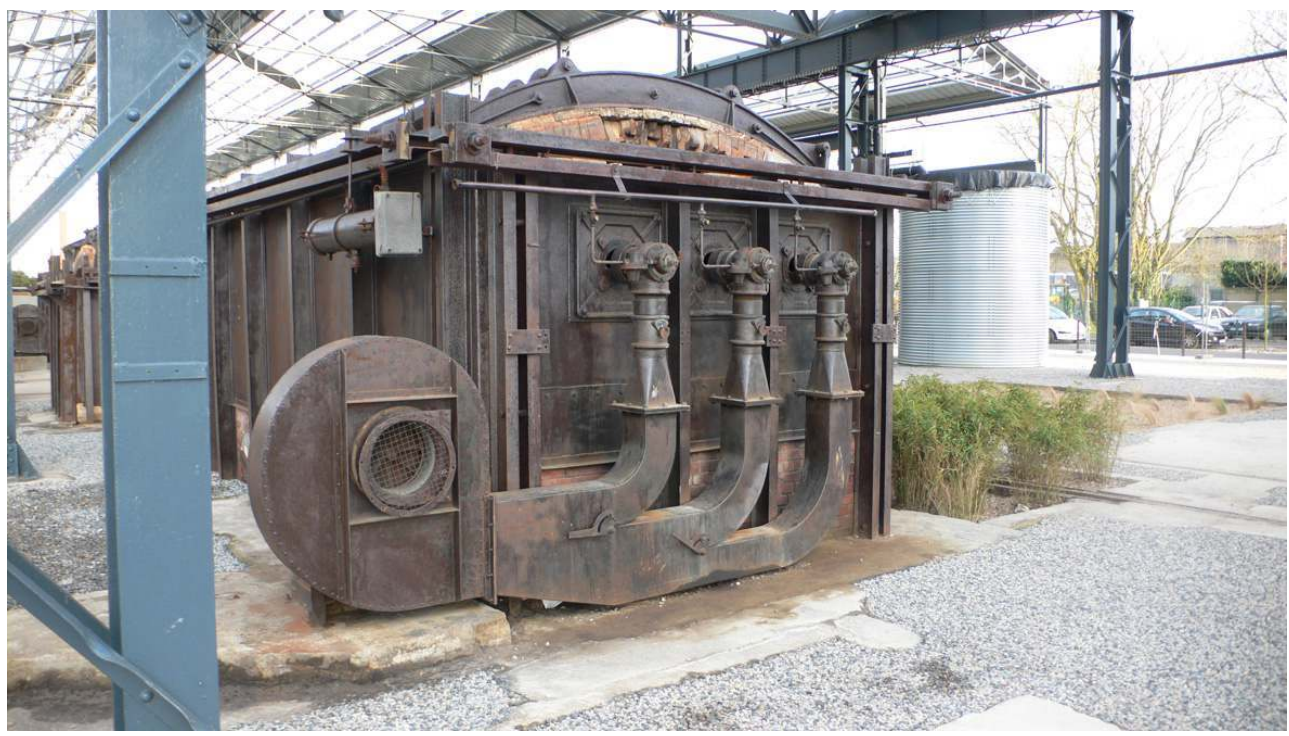

Conservation et réhabilitation de la nef de 1937 et réalisation d'un jardin d'hiver en 2009, Doazoan et Hirchsberger paysagistes. Détail du four de 20 t restauré. Photo Jean-Louis Kerouanton, mars 2009.

\section{Bref rappel historique ${ }^{4}$}

Les frères Babin-Chevaye, fils d'un des fondateurs des Ateliers et Chantiers de la Loire, étaient issus du milieu de la métallurgie et de la construction navale nantaises ${ }^{5}$. D’abord installés sur l'île Gloriette, toute proche du centre historique, ils transfèrent leur fonderie de fer plus au sud, le long de l'axe traditionnel de traversée de la Loire, la Chaussée de la Madeleine, vers 1907-1908, en s'implantant à l'origine à l'est de la rue Dorgère. L'usine connaît ses premiers développements vers l'est, le long de la Boire Toussaint ${ }^{6}$. En 1918 est créée la Société nantaise de construction mécanique et de fonderies réunies (SNCMFR); cette nouvelle raison sociale symbolise le développement d'une industrie étroitement liée dans ses productions et son actionnariat à l'histoire de la construction navale nantaise. Un nouveau bâtiment est édifié en 1921 ; très dégradé, il n'a pas été conservé en 2002. À la fin de l'entre-deux-guerres, vers 1937, le percement du futur boulevard des Martyrs va obliger l'entreprise expropriée à se développer davantage vers l'est, au détriment des bâtiments d'origine de la rue Dorgère. L'usine dirige en même temps sa production vers la fonderie de cuivre et la fabrication des hélices. Trois fours horizontaux à réverbère sont installés, respectivement de 6, 12 et 20 tonnes. Mais les contraintes économiques de la guerre conduisent l'entreprise à se redéployer vers la fonderie de fer. Jusqu'à la rupture de 1980, la SNCMFR poursuit ces deux types de productions. Seules les hélices ou pales d'hélices continuent à être fabriquées dans la partie est du site, reprise tout d'abord par les Fonderies phocéennes. Après des années difficiles et plusieurs reprises, y compris la création d'une société coopérative ouvrière de production (SCOP) éphémère, le site est abandonné en 2001 par le dernier repreneur, Atlantic Industrie, qui laisse les bâtiments et les objets contenus à la Communauté urbaine de Nantes ${ }^{7}$. La collection d'objets en tant que telle, comme toutes les collections de modèles, appartenait en fait aux différents commanditaires. En prévision du déménagement, l'industriel avait sollicité ses clients 
pour savoir ce qui devait être gardé et faire partie du transfert. Les anciens chantiers français fabriquant des hélices étant fermés, comme les Ateliers et Chantiers de Bretagne ${ }^{8}$, la demande était bien entendu caduque ; c'est seulement pour le fabricant suédois Kamewa que cela représentait un enjeu important. En choisissant de ne garder que les modèles inférieurs à cinq ans, il se défaisait sans le savoir, au profit de la collectivité, d'un ensemble technique et industriel de première importance, puisque certains, toujours utilisables, tout en étant propriété publique, ont pu à l'occasion resservir aux fonderies désormais installées à Chantenay.

Figure 6

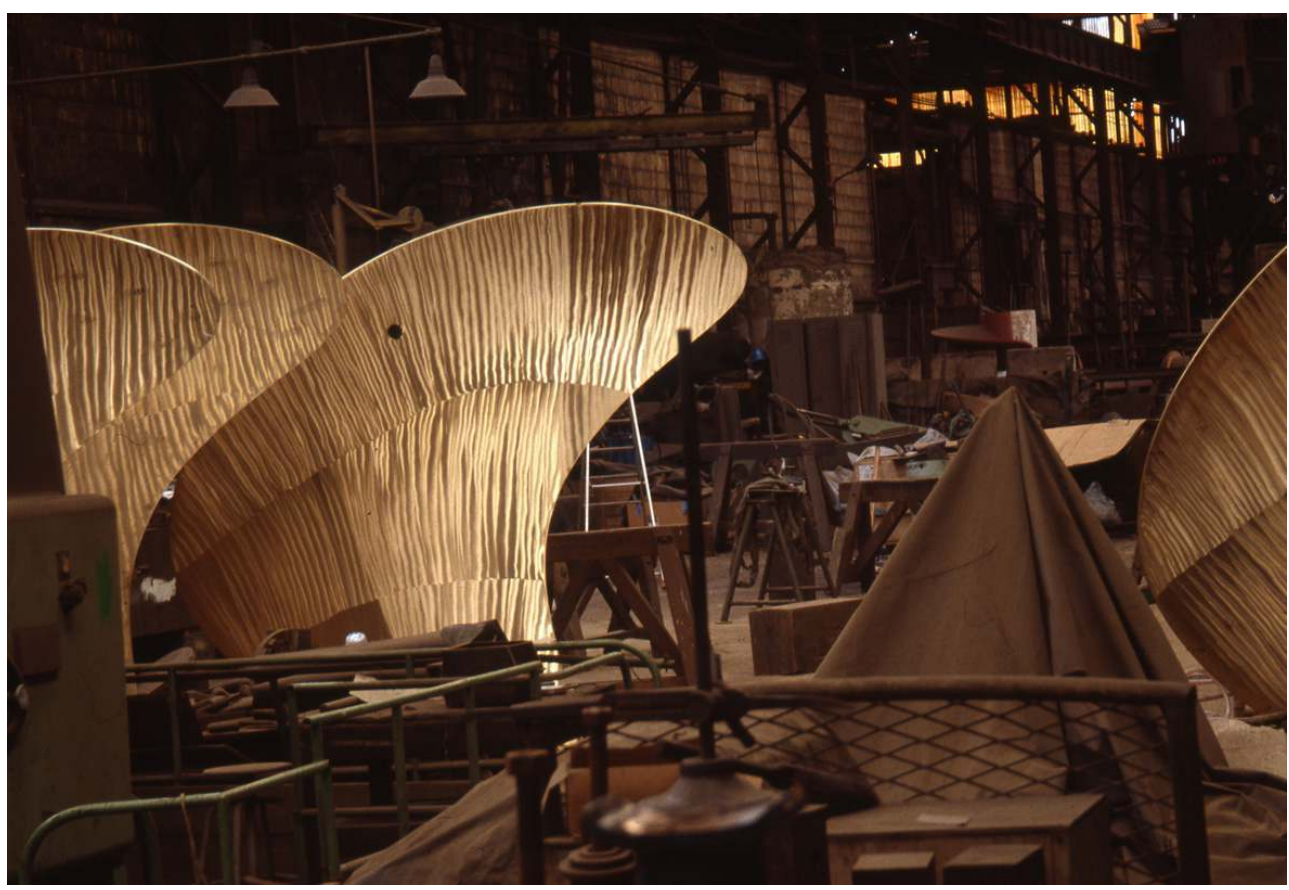

Vue intérieure de l'usine. Photo Jean-Louis Kerouanton, mars 2001.

(c) Jean-Louis Kerouanton.

\section{La découverte de l'usine}

L'ambiance de la fonderie était elle-même assez particulière: comme toujours en ces lieux semblaient se juxtaposer sans heurts les tours et les machines d'essai les plus modernes avec les installations du procédé lui-même, fosses de coulée, fours horizontaux à réverbère qui paraissaient d'un autre âge, le tout curieusement habillé et lissé par la couleur des sables noirs de fonderie, partout sur le sol. Et puis trônaient les hélices et les pales d'hélices, dont les alliages en cours de polissage brillaient d'un éclat somptueux (fig. $\mathbf{n}^{\circ}$ 6). Pourquoi ne pas évoquer ce plaisir? Les objets fabriqués ici étaient d'une pureté et d'une élégance rares, faisant oublier immédiatement leur future fonction mécanique. Mais la visite se poursuivant dans les bâtiments, la surprise et l'enchantement n'étaient pas terminés. La découverte du magasin de modèles a été pour moi un véritable choc. L'accumulation de plus d'une centaine de chefs-modèles, dont certains dépassaient les deux mètres de hauteur, n'était ni plus ni moins qu'un magnifique jardin de sculptures (fig. $n^{\circ} 7$ ). 
Figure 7

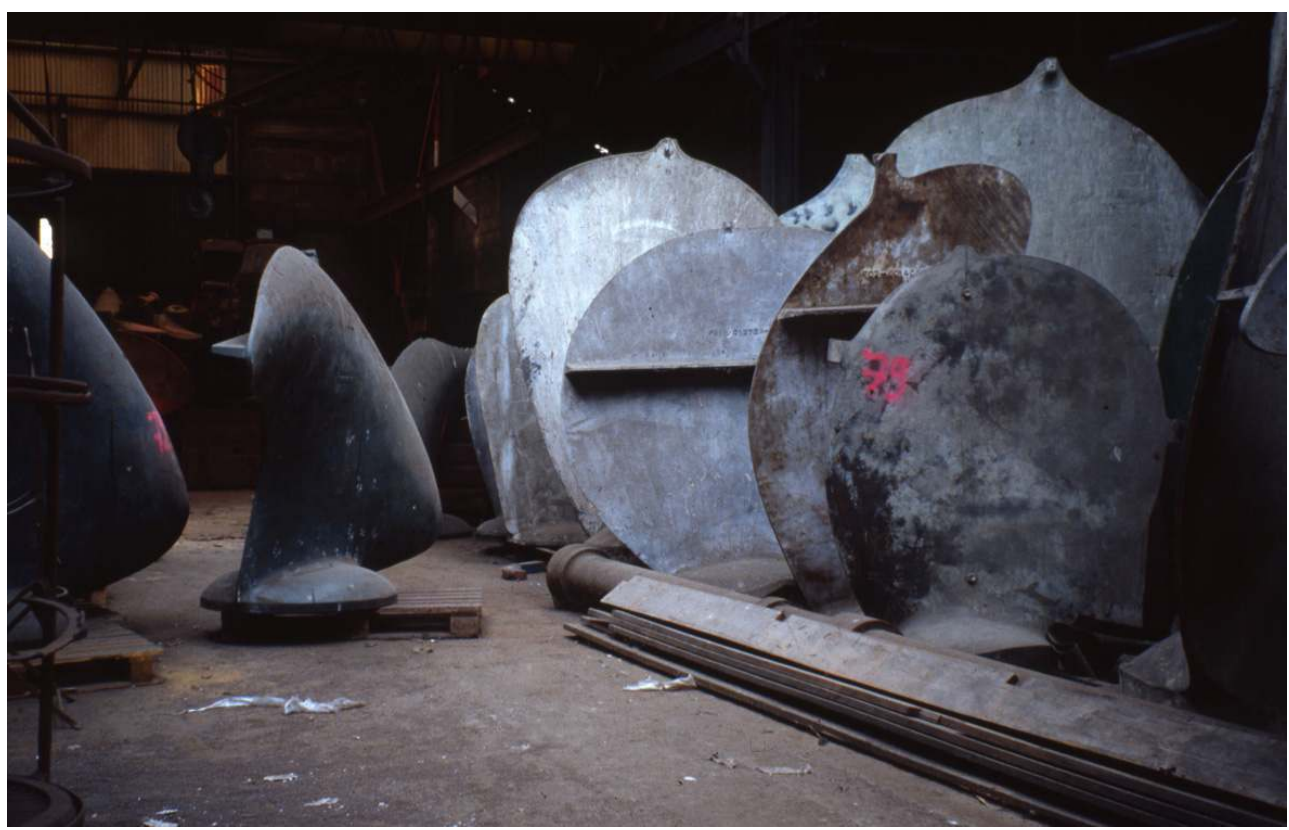

Vue d'ensemble du magasin de modèles. Photo Jean-Louis Kerouanton, mars 2001.

(c) Jean-Louis Kerouanton.

5 C'est l'ensemble de ces données, qu'il a fallu documenter au plus vite, qui nous ont permis d'assurer la sauvegarde d'un patrimoine qui s'avérait exceptionnel. Les Fonderies étaient en effet en France et en Europe une des plus importantes usines pour les alliages de cuivre en capacité de fonte (fig. $\mathbf{n}^{\circ} \mathbf{8}$ ).

Figure 8

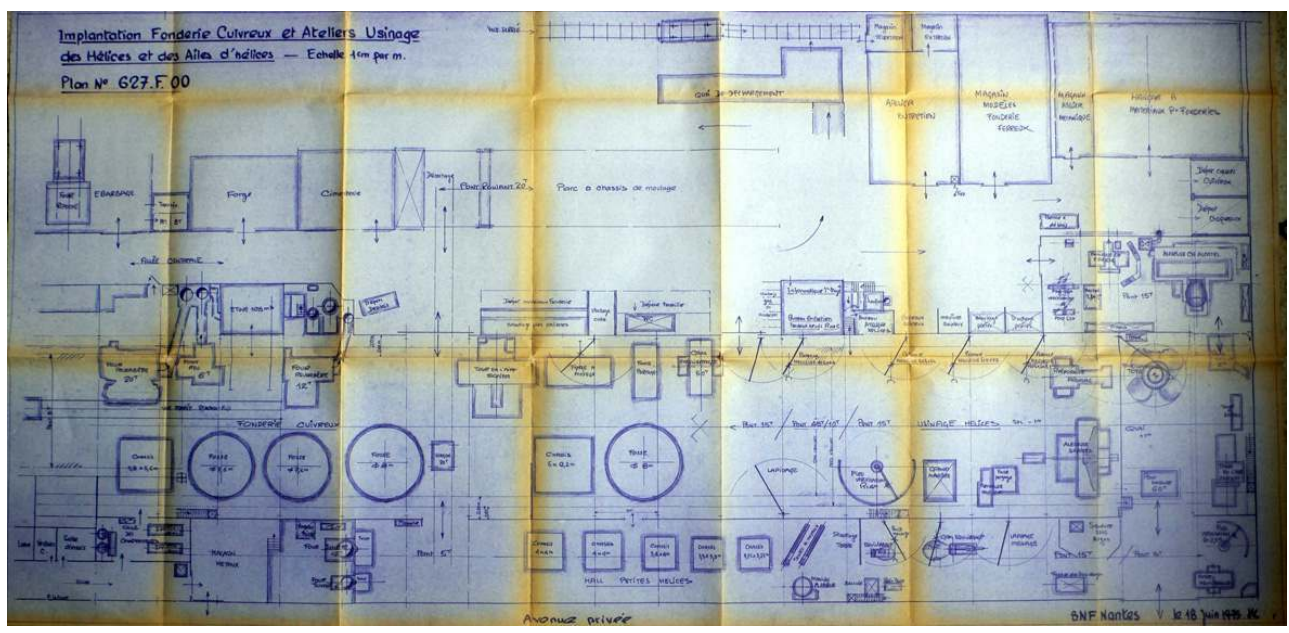

Implantation Fonderie Cuivreux et Ateliers Usinage, juin 1975, Plan, juin 1975, archives privées. Photo Jean-Louis Kerouanton.

(c) Jean-Louis Kerouanton.

6 Mis en action simultanément, les fours permettaient en effet des coulées de 40 tonnes, ce qui correspond aux plus grosses hélices des plus gros navires de la planète. Capacité mais aussi qualité, l'usine détenait les meilleurs marchés et les détient toujours dans son 
nouveau site. L'étude menée par la suite a montré qu'en travaillant de manière privilégiée avec Kamewa en Suède ${ }^{9}$ (désormais Rolls-Royce Marine), les productions locales permettaient l'assemblage des groupes propulseurs de toute la nouvelle génération des grands paquebots dont la fin des années 1980 a marqué la renaissance dans le monde entier. L'usine avait beau à l'époque être bien bousculée par le contentieux autour des hélices du Charles de Gaulle ${ }^{10}$, elle restait de toute évidence au premier rang des producteurs européens et mondiaux en la matière.

Figure 9

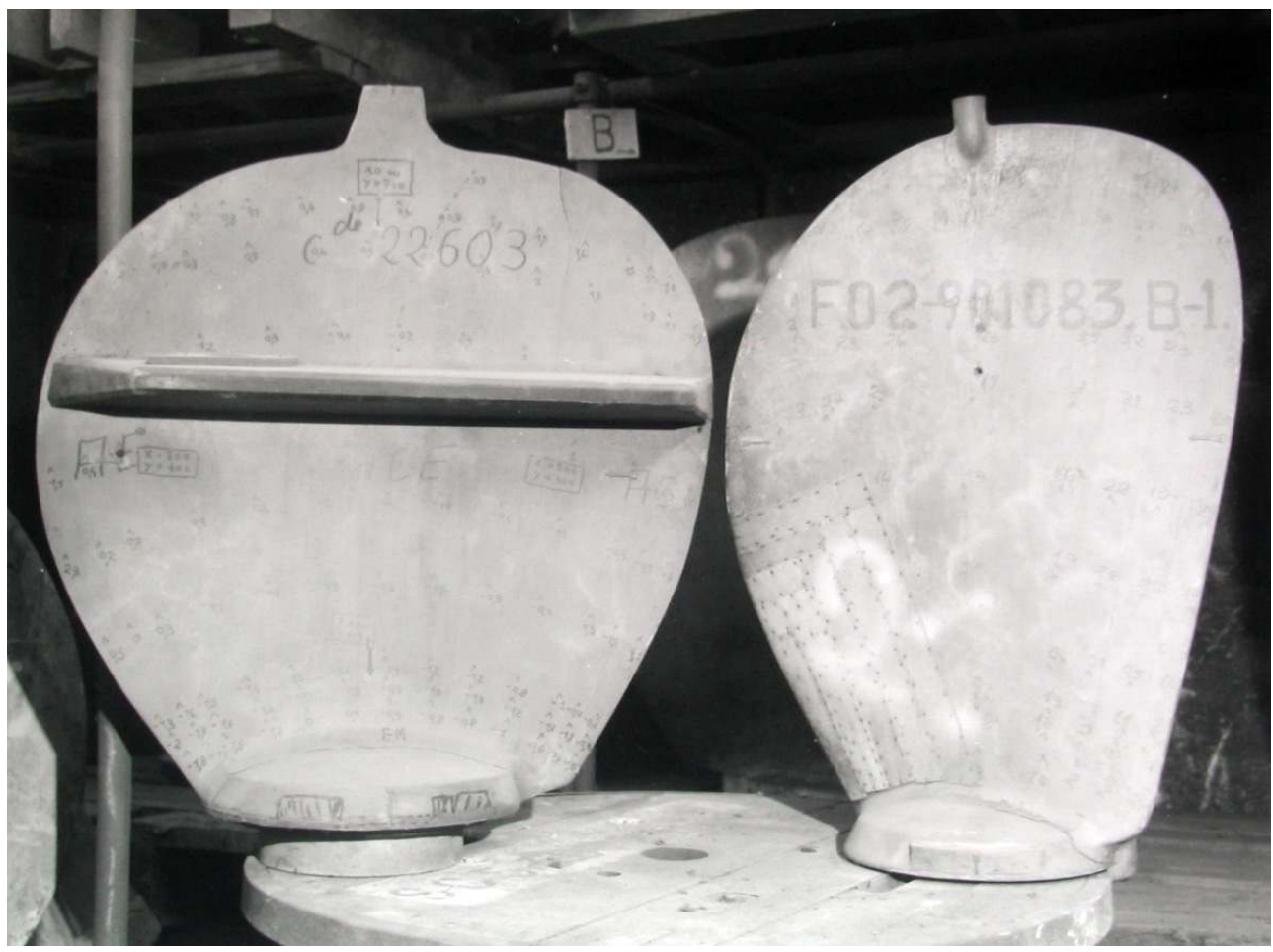

Exemples de chefs-modèles de pales d'hélice, hauteur $90 \mathrm{~cm}$ environ, modèles volés en 2005. Photo Inventaire François Lasa, 2001.

(c) Région Pays de la Loire, Inventaire général. 
Figure 10

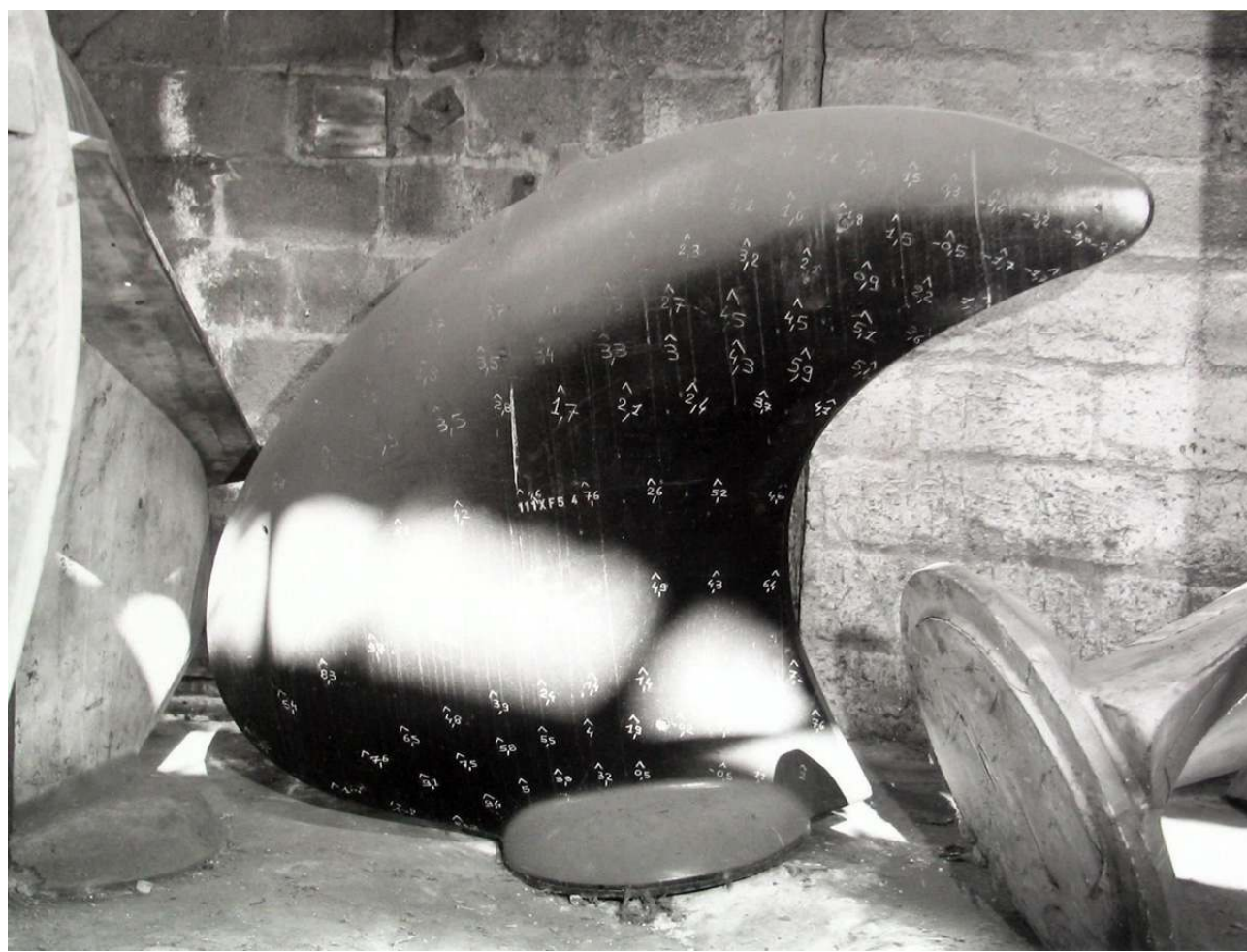

Exemple de chef-modèle récent de type en « aile de requin », skew back. Dimensions de ce modèle $163 \times 210 \times 68$, modèle de pale d'hélice, bois assemblé peint, noir. Ce modèle a permis de réaliser en deux fois (1998 et 1999) 24 pales d'hélices, de type faucille, pour l'entreprise suédoise Kamewa (désormais intégrée à Rolls-Royce Marine), commande 901669 ou 901895111 XF 54. Les six bateaux, chacun équipé de deux hélices à quatre pales, sont des porte-conteneurs lancés par les chantiers hambourgeois SIETAS en 1998 et 2000. Photo Inventaire François Lasa, 2001.

(c) Région Pays de la Loire, Inventaire général.

7 Le travail commun mené par la DRAC des Pays de la Loire et la Mission île de Nantes a permis d'identifier les éléments principaux et de distinguer les différentes typologies d'objets : chefs-modèles de pales d'hélices de plus ou moins grande dimension, inférieurs à $1 \mathrm{~m}$ de hauteur pour les plus petites (fig. $\mathbf{n}^{\circ}$ 9) mais parfois approchant ou dépassant les deux mètres pour les plus grandes (fig. $\mathbf{n}^{\circ} \mathbf{1 0}$ ). Il s'agit ici, même pour les "petits » modèles, d'éléments correspondant à des navires de belle taille; si l'on rajoute le moyeu à la longueur de pale, on obtient des diamètres de presque $2,50 \mathrm{~m}$. Que dire alors de plus gros modèles - qui correspondent à des assemblages de 4 ou $5 \mathrm{~m}$ de diamètre - permettant des poussées de plusieurs milliers, voire plusieurs dizaines de milliers de chevaux? 
Figure 11

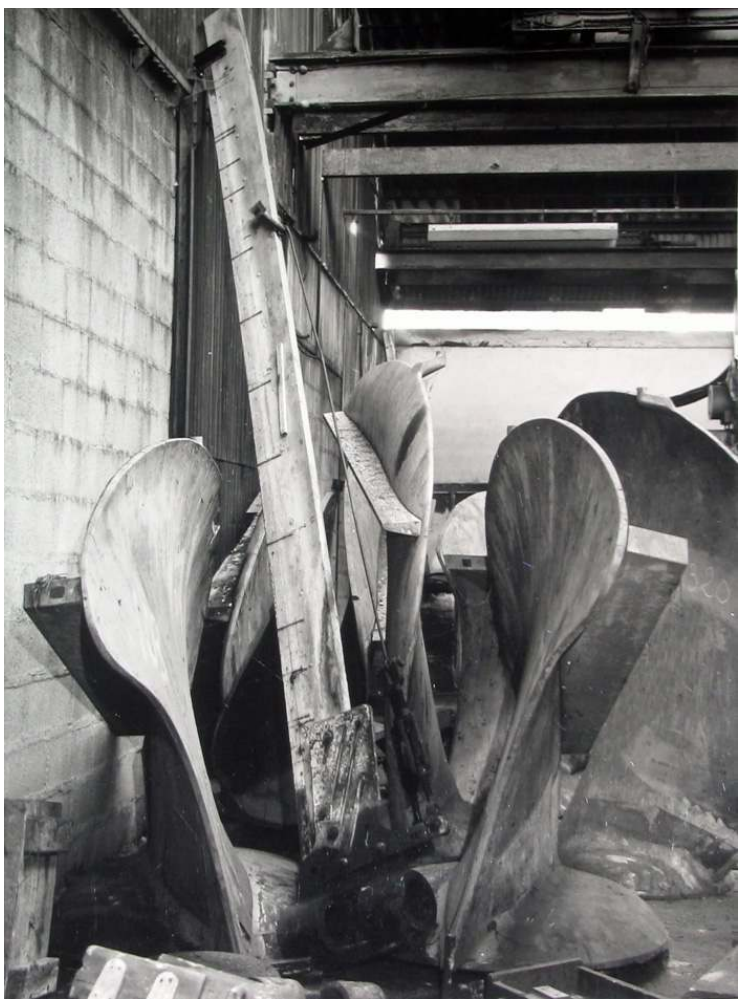

Stockage des modèles : au milieu une planche à trousser de grande dimension, difficilement lisible. Photo Inventaire François Lasa, 2001.

(c) Région Pays de la Loire, Inventaire général. 
Figure 12

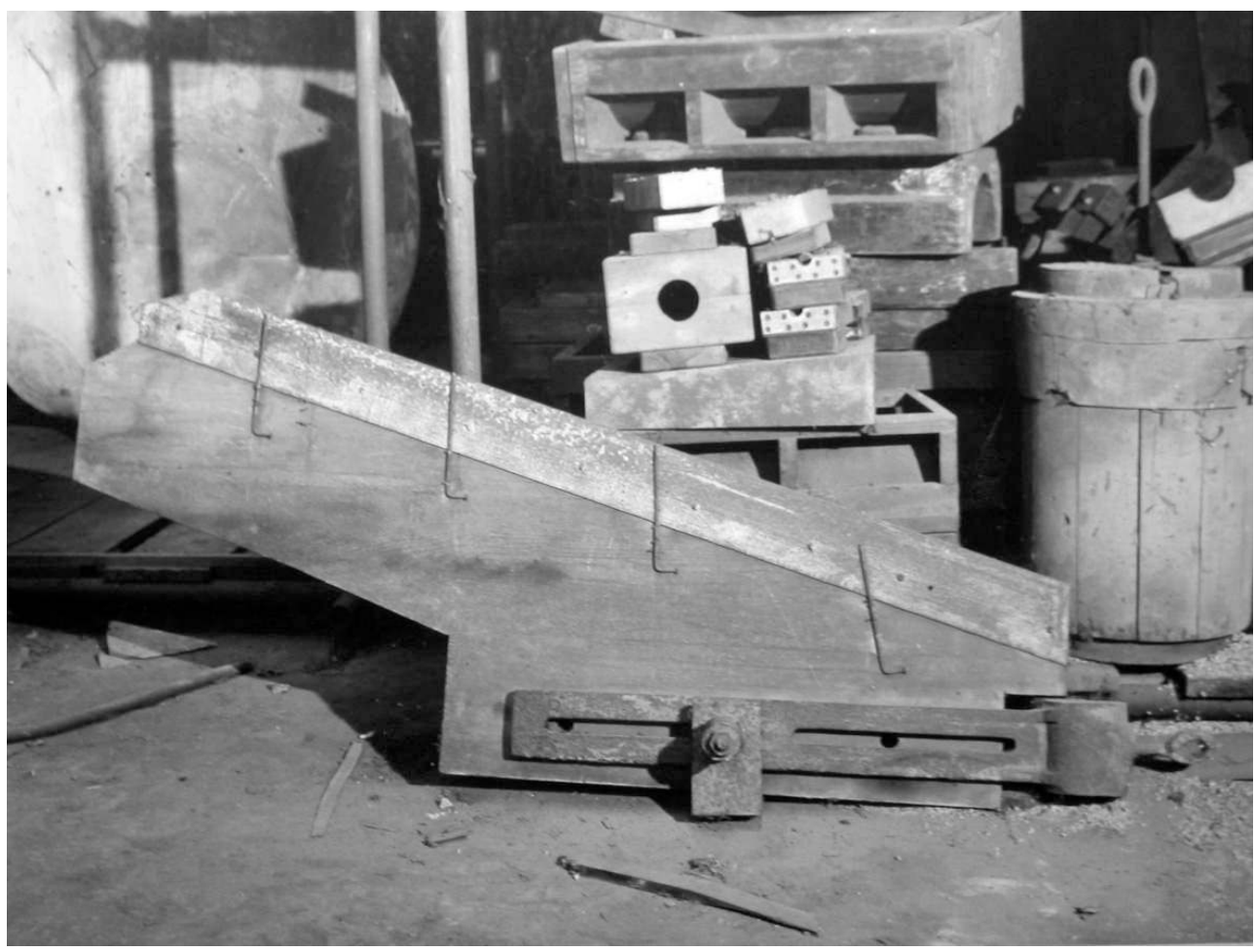

Stockage des modèles : planche à trousser complète, avec son trusquin pour la mise en rotation sur l'axe, et les points de repère pour les gabarits de section. Photo Inventaire François Lasa, 2001.

(c) Région Pays de la Loire, Inventaire général.

Il y avait d'autres objets moins immédiatement identifiables, les planches à trousser (fig. $\left.\mathbf{n}^{\circ} 11\right)$, malgré des dimensions approchant pour certaines les trois, voire quatre mètres pour la planche de l'hélice du Foch, ou de toute façon bien mystérieuses pour le profane quand on pouvait les examiner de près (fig. $\mathbf{n}^{\circ} \mathbf{1 2}$ ) que dire encore de ces lames métalliques (fig. $\mathbf{n}^{\circ}$ 13) qui, pourtant bien identifiées sur leur flancs, relevaient d'un ensemble manifestement organisé correspondant à la Drague Mexique? 
Figure 13

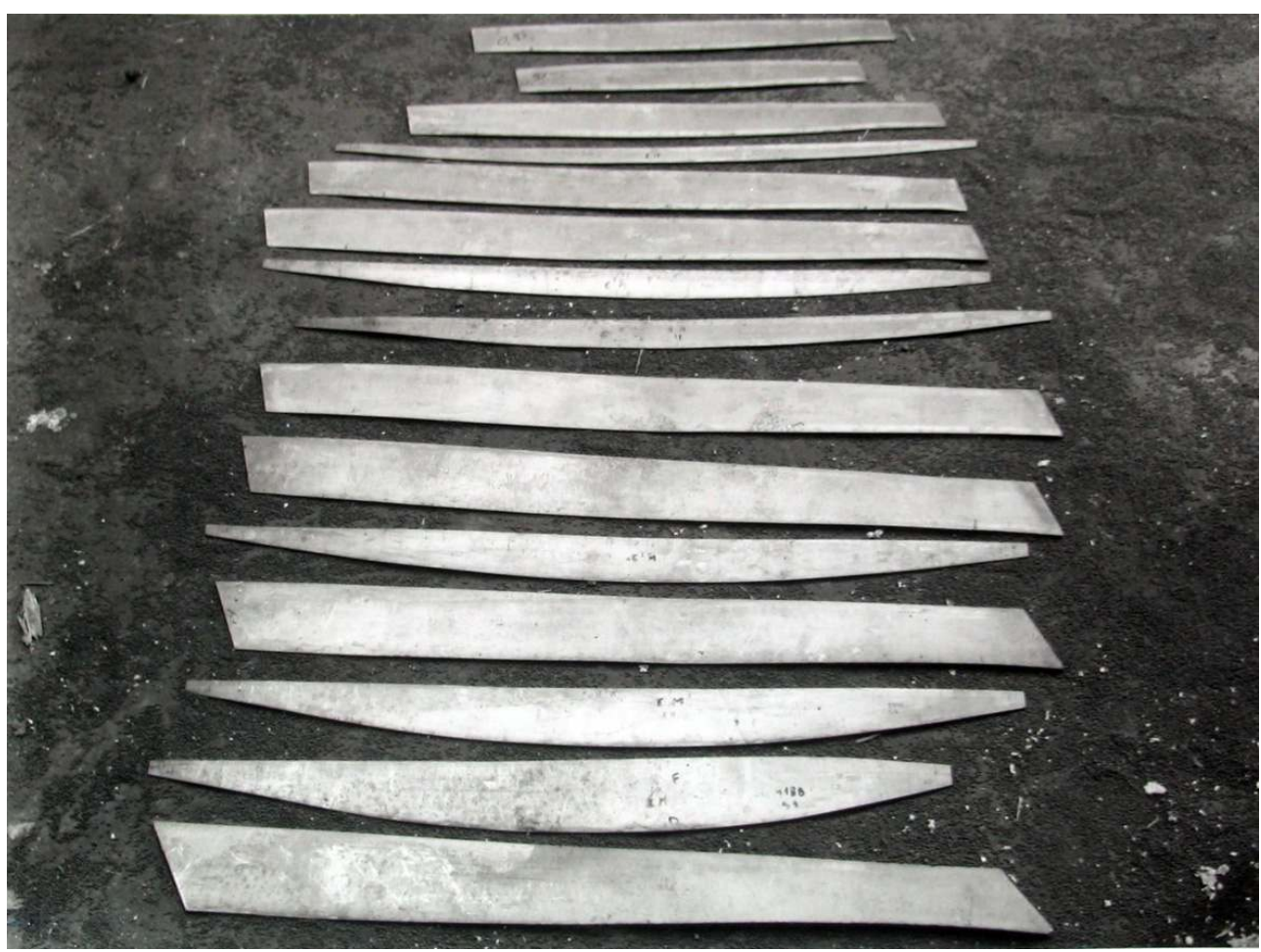

Gabarits de section de la Drague Mexique, 14 éléments, entre 40 et $80 \mathrm{~cm}$ de long, par 5 à $10 \mathrm{~cm}$ de large, lames de métal. Photo Inventaire François Lasa, 2001.

(c) Région Pays de la Loire, Inventaire général.

9 L'aide précieuse de la direction de l'établissement et de certains ouvriers s'est avérée irremplaçable pour la compréhension des procédés de fonderie ${ }^{11}$. Par contre, les archives sont relativement silencieuses quant aux commandes elles-mêmes. Les indications quant à la destination finale (type de navire) ne sont pas toujours présentes et il faudra un long travail de recoupement avec d'autres sources pour identifier le parcours complet des productions à partir des numéros et des dates de commande. Il faut croiser les inscriptions peintes ou fixées par lettres de plomb sur le modèle avec les registres de commande conservés. Parfois, on a l'indication du type de navire ou même de son nom : c'est ainsi qu'on a pu retrouver les modèles des hélices de la série des grands paquebots Majesty of the Seas qui ont largement contribué au nouveau décollage des Chantiers de l'Atlantique au tournant des années $1990^{12}$. Les recoupements peuvent se faire par d'autres moyens, l'exemple présenté en image a été recoupé en 2002 avec des informations sur Internet à partir du numéro de commande. Mais il ne s'agit à l'heure actuelle que de simples sondages qu'il faudrait reprendre entièrement dans le cadre d'une étude systématique. 


\section{Figure 14}

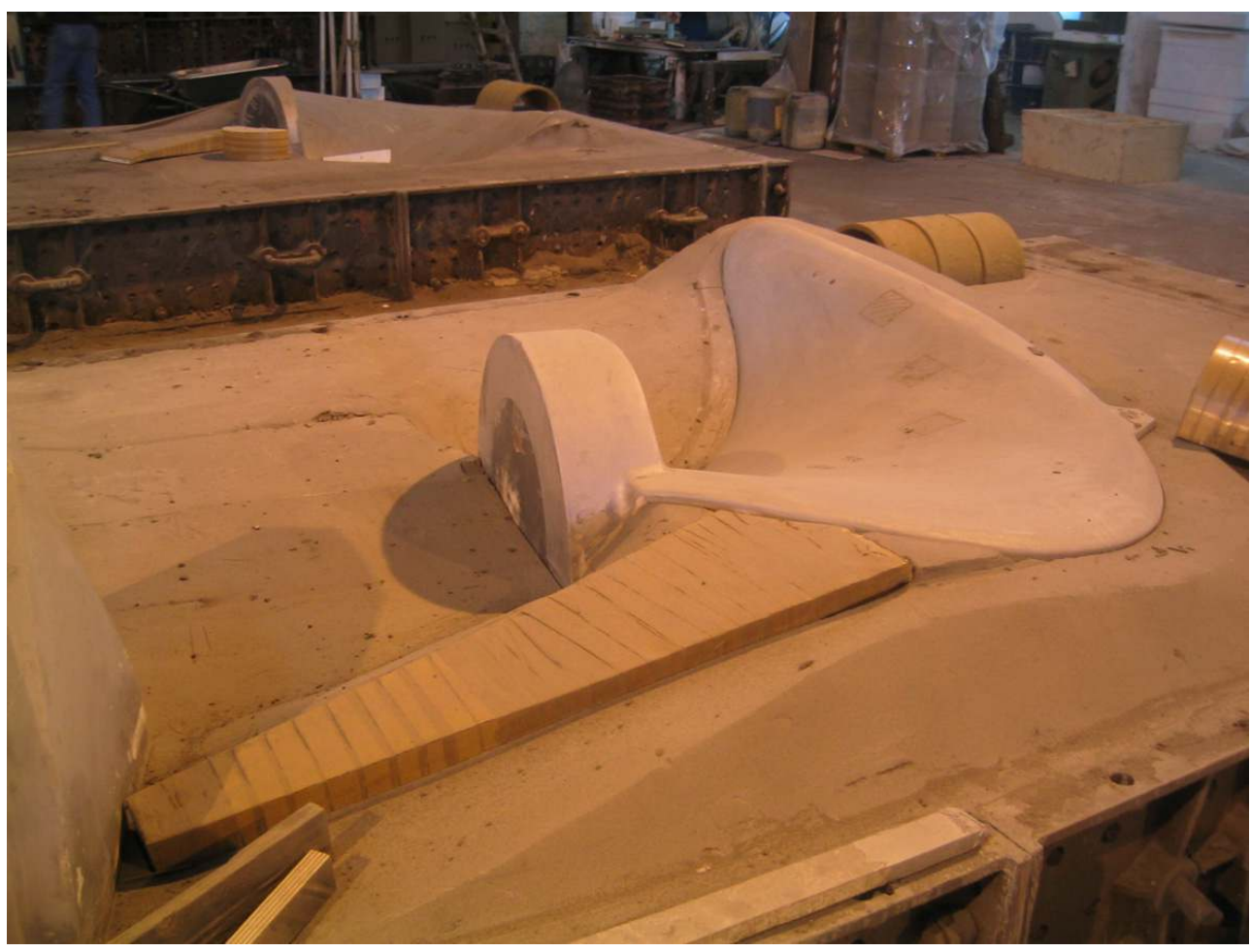

Préparation d'une coulée de pale d'hélice, Atlantic Industrie, Nantes Chantenay, le modèle est placé dans le sable : au premier plan, matérialisation de l'entonnoir de coulée, le vide pour la masselotte n'est pas encore mis en forme, il sera nécessaire à l'épanchement et au retrait du surplus de métal. Photo Jean-Louis Kerouanton, 2005.

(c) Jean-Louis Kerouanton. 
Figure 15

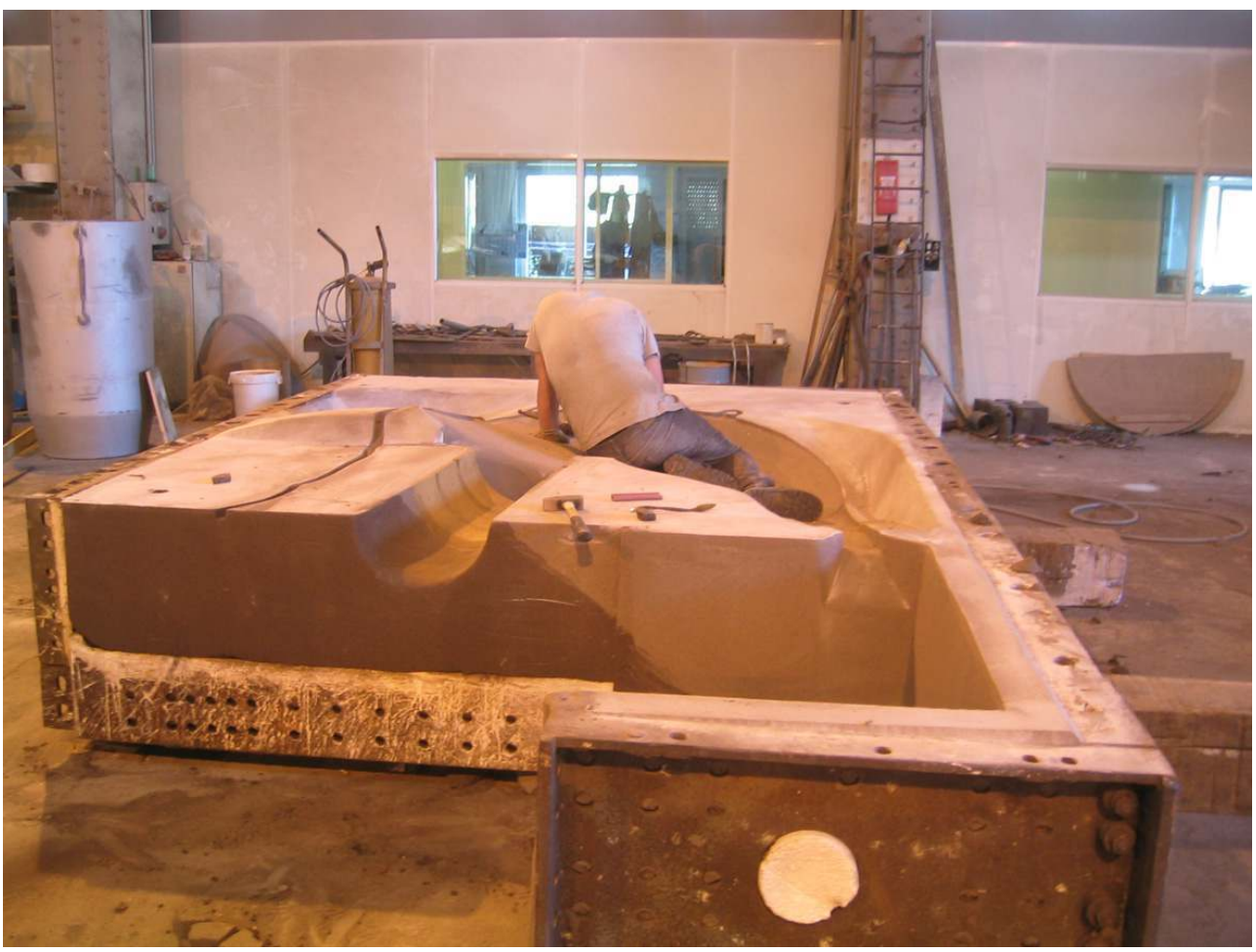

Préparation d'une coulée de pale d'hélice, Atlantic Industrie, Nantes Chantenay, le modeleur finit le moule manuellement une fois le modèle enlevé ; on voit bien au premier plan l'importance du volume de la masselotte. La rigole à gauche correspond à un évent. Photo Jean-Louis Kerouanton, 2005.

(c) Jean-Louis Kerouanton.

10 Les modèles de pales ne présentaient aucune difficulté quant à leur première interprétation. Il s'agissait de fonderie au sable «classique» dont le moule conçu par mise en place du modèle dans le sable correspondait à une technique déjà vue par ailleurs (fig. $\left.\mathbf{n}^{\circ} \mathbf{1 4}, \mathbf{n}^{\circ} \mathbf{1 5}\right)$, même si la dimension des pièces coulées était tout à fait hors normes, nécessitant la manipulation de poches de plusieurs tonnes contenant l'alliage de cuproaluminium jusqu'au châssis. 


\section{Figure 16}

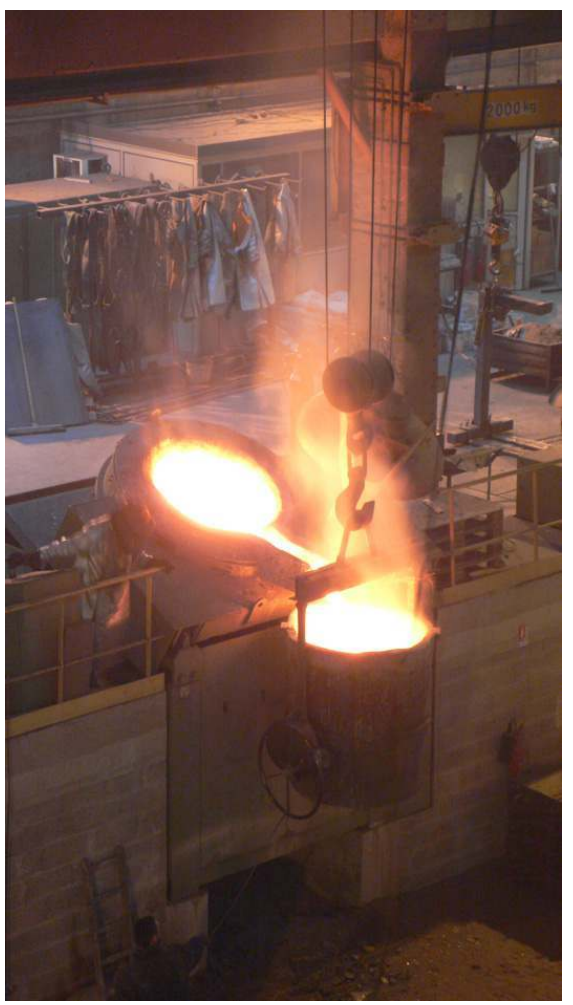

Les étapes successives de la coulée verticale d'une pale aujourd'hui. Versement de l'alliage fondu dans la poche de transfert à partir du four électrique. Photo Jean-Louis Kerouanton, 2008.

(c) Jean-Louis Kerouanton. 
Figure 17

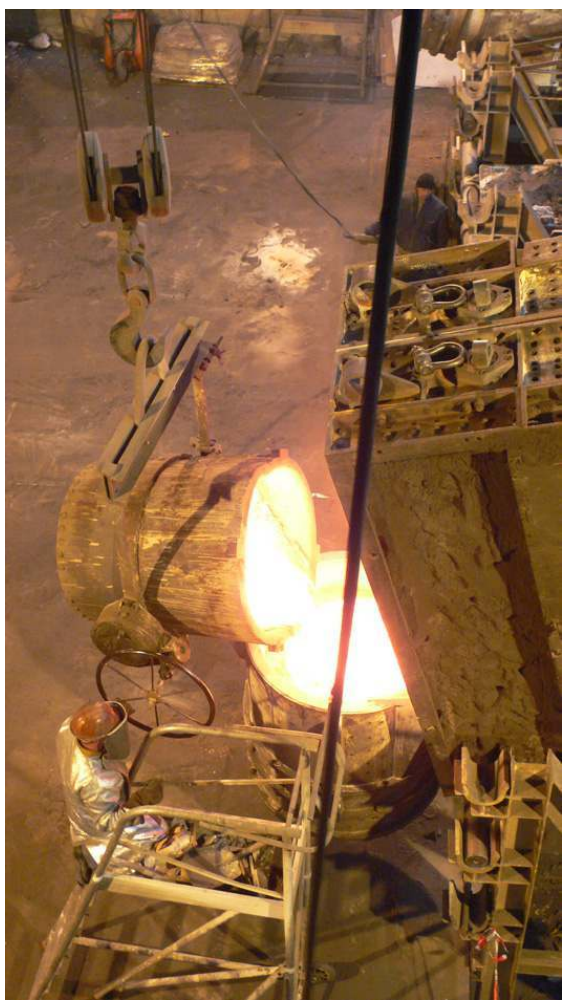

Les étapes successives de la coulée verticale d'une pale aujourd'hui. Transfert du métal liquide dans la poche réservoir du châssis ; le moule est totalement redressé. Photo Jean-Louis Kerouanton, 2008. (c) Jean-Louis Kerouanton.

11 Aujourd'hui, pour contrôler davantage les coulées, les pales sont fondues dans des châssis mobiles, qui tournent verticalement au fur et à mesure du versement de l'alliage (fig. $\mathbf{n}$ $\cdot 16,17,18,19,20)$. 


\section{Figure 18}

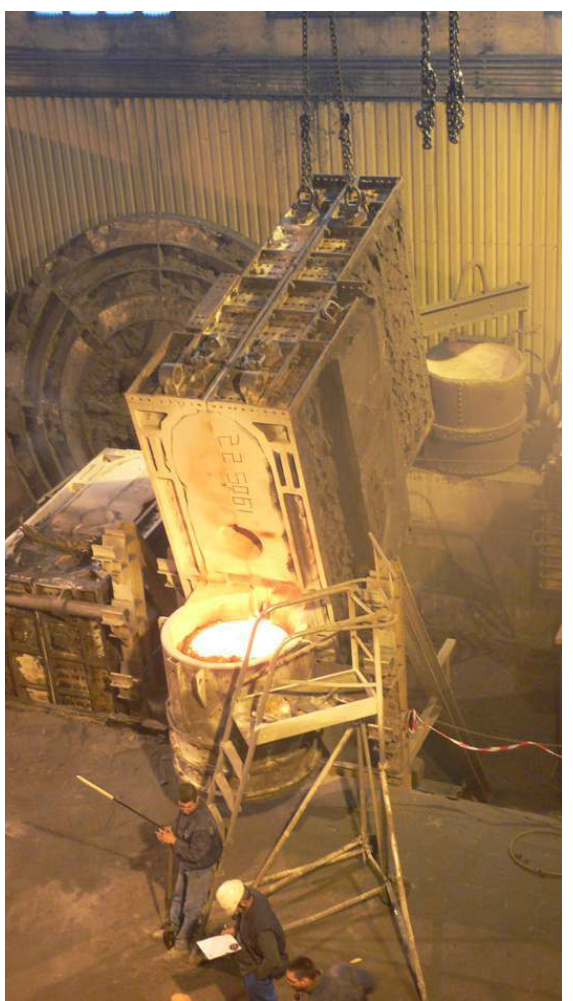

Les étapes successives de la coulée verticale d'une pale aujourd'hui. Après vérification de la température, la coulée va pouvoir commencer. Photo Jean-Louis Kerouanton, 2008.

(c) Jean-Louis Kerouanton.

\section{Figure 19}

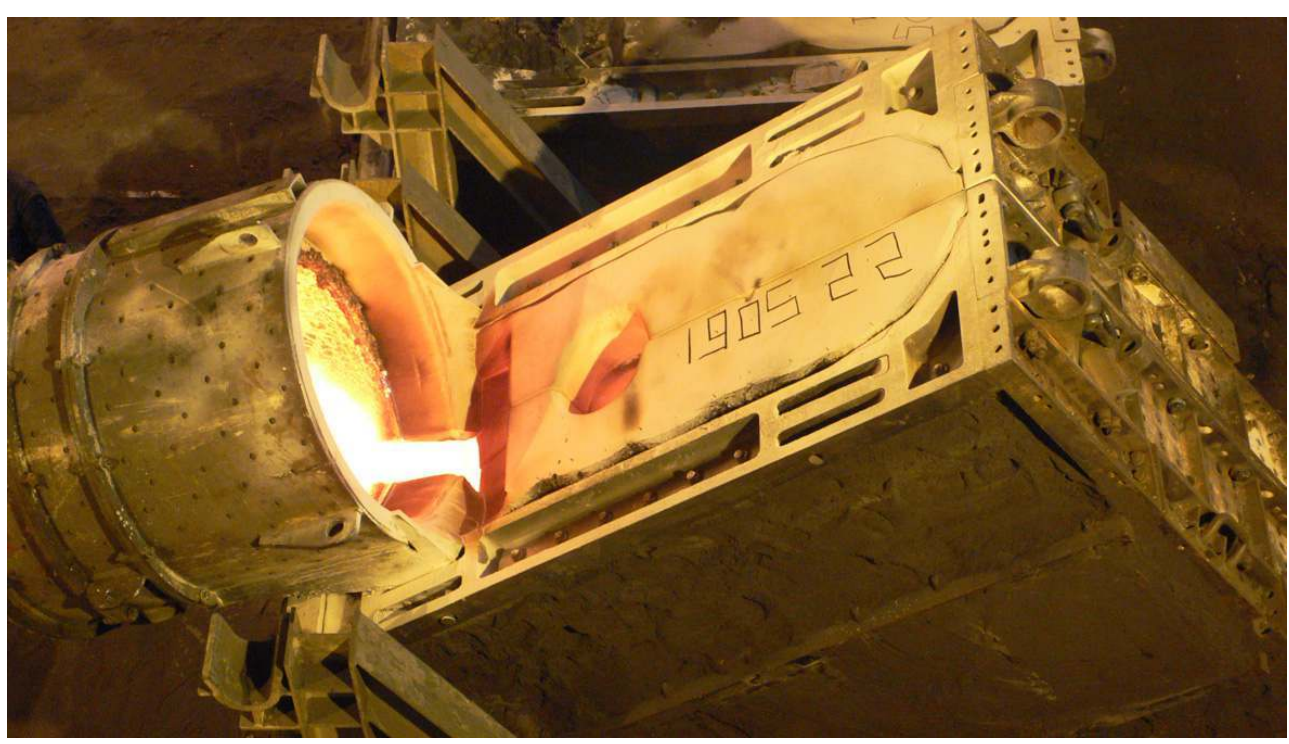

Les étapes successives de la coulée verticale d'une pale aujourd'hui. La coulée s'étale progressivement au fur et à mesure de la rotation du châssis. Photo Jean-Louis Kerouanton, 2008. (c) Jean-Louis Kerouanton. 


\section{Figure 20}

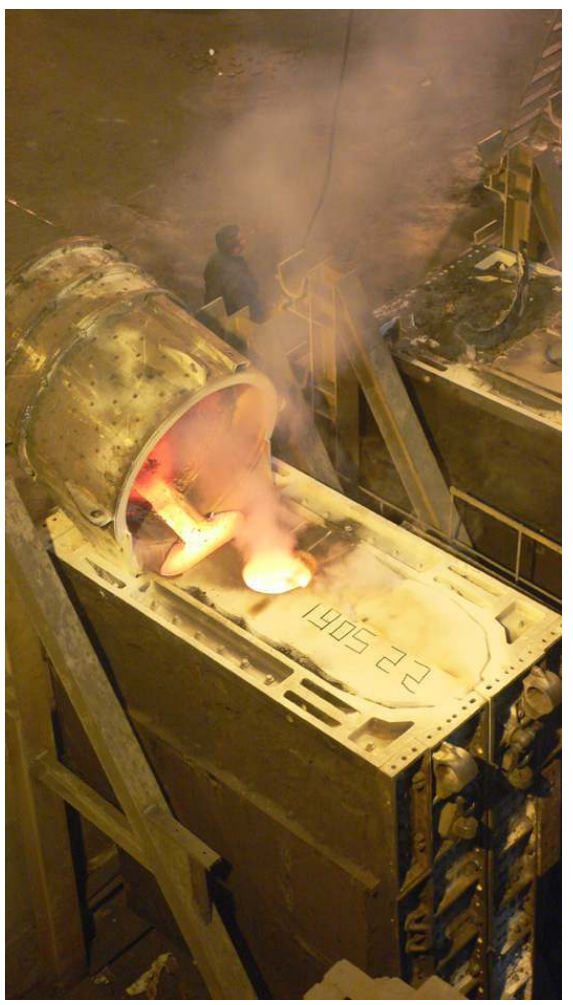

Les étapes successives de la coulée verticale d'une pale aujourd'hui. La coulée se termine alors que le moule est totalement redressé, le surplus d'alliage remonte au centre par la cheminée de la masselotte. Photo Jean-Louis Kerouanton, 2008.

(c) Jean-Louis Kerouanton. 
Figure 21

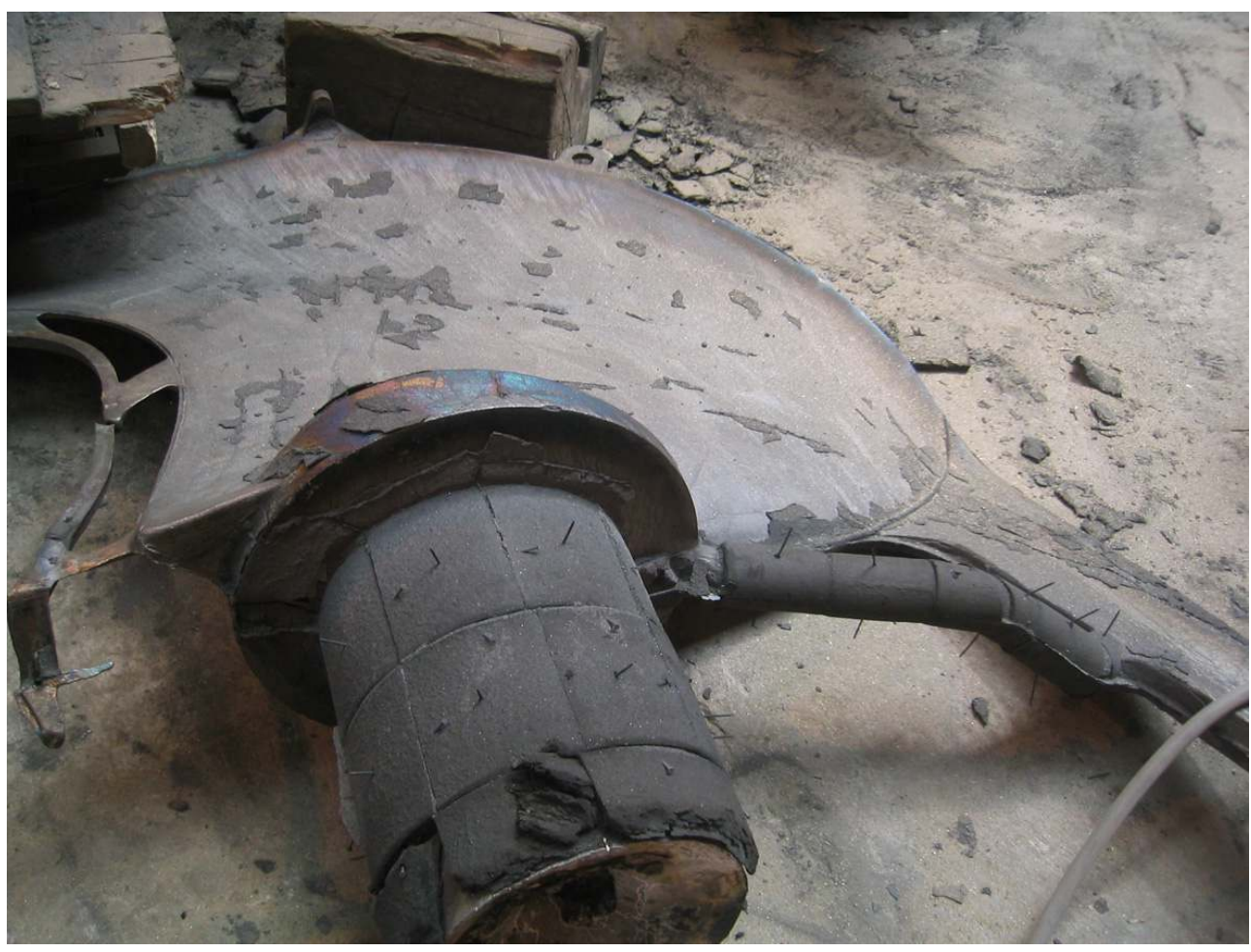

Après la coulée. Récupération de la pale brute de fonderie après refroidissement : de droite à gauche sont visibles autour de la pale l'entonnoir de coulée, la masselotte au premier plan et les évents sur la gauche. Photo Jean-Louis Kerouanton, 2005.

(c) Jean-Louis Kerouanton.

12 Après refroidissement et démoulage, l'objet obtenu doit être ébarbé, débarrassé de sa masselotte, avant d'être contrôlé et poli très finement (fig. $\mathbf{n}^{\circ} \mathbf{2 1}, \mathbf{2 2}, \mathbf{2 3}$ ). 
Figure 22

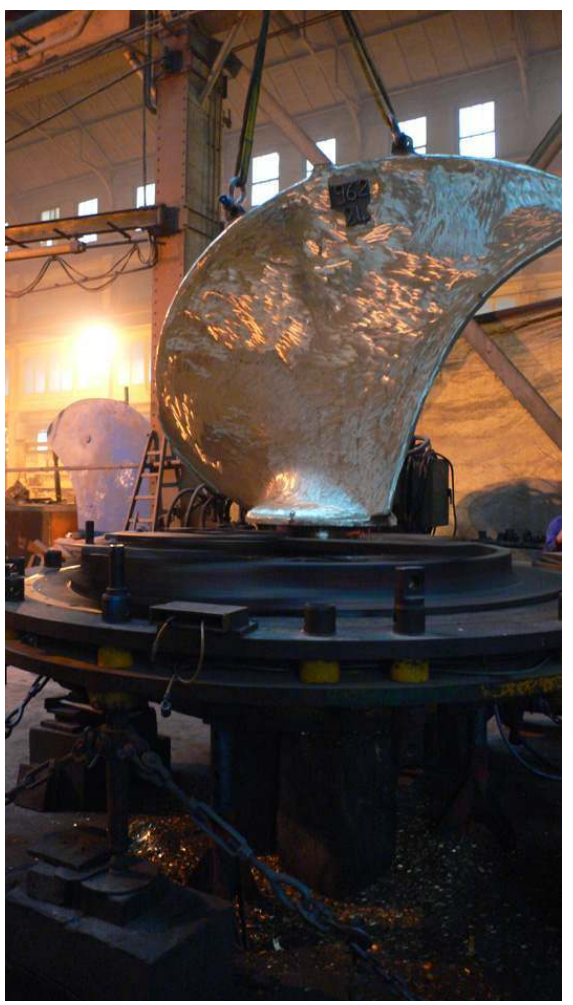

Après la coulée. Découpe mécanique au tour de la masselotte, la pale a fait l'objet d'un ébarbage et d'un nettoyage sommaire. Photo Jean-Louis Kerouanton, 2008.

(c) Jean-Louis Kerouanton. 


\section{Figure 23}

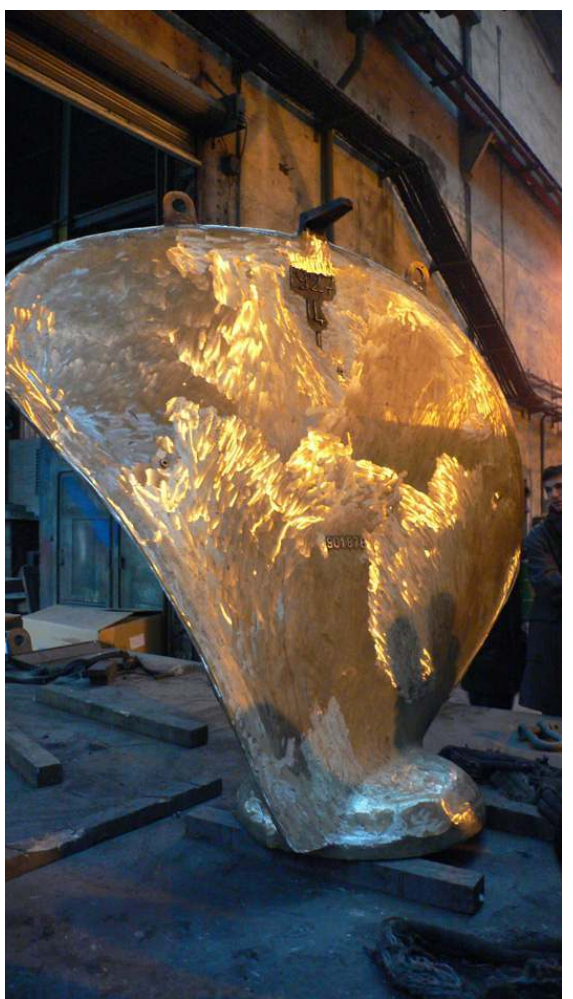

Après la coulée. La pale d'hélice est prête pour la finition. Photo Jean-Louis Kerouanton, 2008.

(c) Jean-Louis Kerouanton.

Les objets du troussage ne révélaient par contre rien du procédé de conception du moule au premier regard. Les explications obtenues sur place jetèrent les bases de la compréhension, non seulement de la question pratique de l'hélice au trousseau mais aussi, finalement, des enjeux de la conception des hélices ou des pales en général. Que se passait-il en effet? Au fond d'une fosse, il s'agit bien de modeler le sable uniquement à partir des données dimensionnelles fournies par le concepteur. 


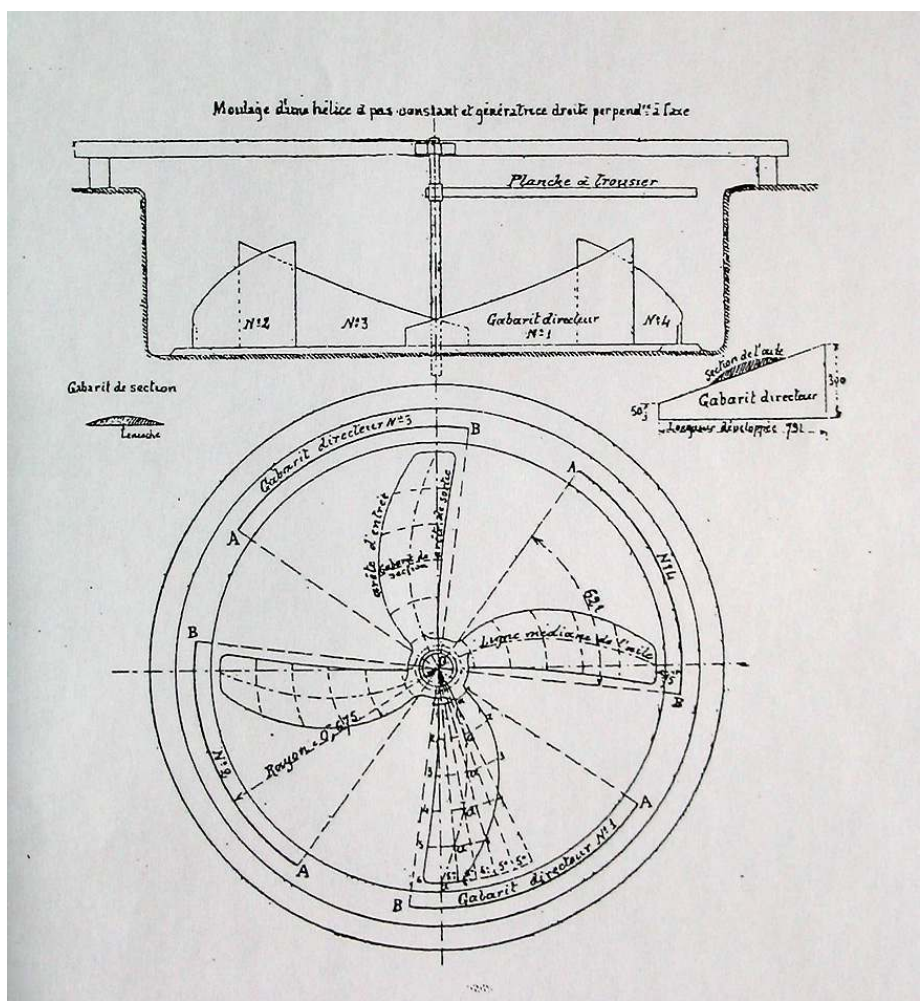

Schéma du moulage au trousseau d'une hélice à quatre ailes. CHERON, Paul. AIDE-MÉmoIRE

MARTINenq Des Constructions naVAles. Paris : Société d'éditions géographiques, maritimes et coloniales, 1931, t. 1, p. 814

Il n'est à la limite pas besoin de dessiner au préalable l'hélice en tant que telle puisque ce qui compte dans l'élaboration, ce sont seulement ses dimensions, ses plans principaux, le galbe de chaque aile mise en place de manière sectionnelle avec des gabarits correspondant aux coupes successives à espace régulier. Il s'agit donc là de calculs et de l'application pratique de ces calculs, avec cette médiation indispensable qu'est le savoirfaire du modeleur pour l'établissement du moule, répétons-le encore, sans modèle (fig. $\mathbf{n}$ -24).

La première étape consiste à placer les grands gabarits de direction à la périphérie de la fosse pour donner l'inclinaison générale de chaque pale. La planche à trousser repasse ensuite avec des clous qui tracent dans le sable les emplacements concentriques des gabarits de section, avec lesquels on va former le galbe définitif de la pale (fig. $\mathbf{n}^{\circ} \mathbf{2 5}, \mathbf{n}$ - 26). S'il est possible de retrouver des modèles pour les pales d'hélices du Majesty of the Seas, ce n'est donc pas le cas pour les modèles d'hélices du France (fig. $\mathbf{n}^{\circ} 27$ ) ou du Clemenceau (fig. n 28), réalisées à Nantes vers 1960 en « Nantial », la variante d'alliage de cupro-aluminum déposée par l'entreprise. Seules restent la planche à trousser du Foch et, si on peut l'identifier, celle du France, et surtout dans les registres de l'entreprise, les caractéristiques de la commande. C'est dire l'importance du calcul et du modèle théorique dans l'élaboration de ces objets, importance théorique qui s'applique bien à l'ensemble de la production. 
Figure 25

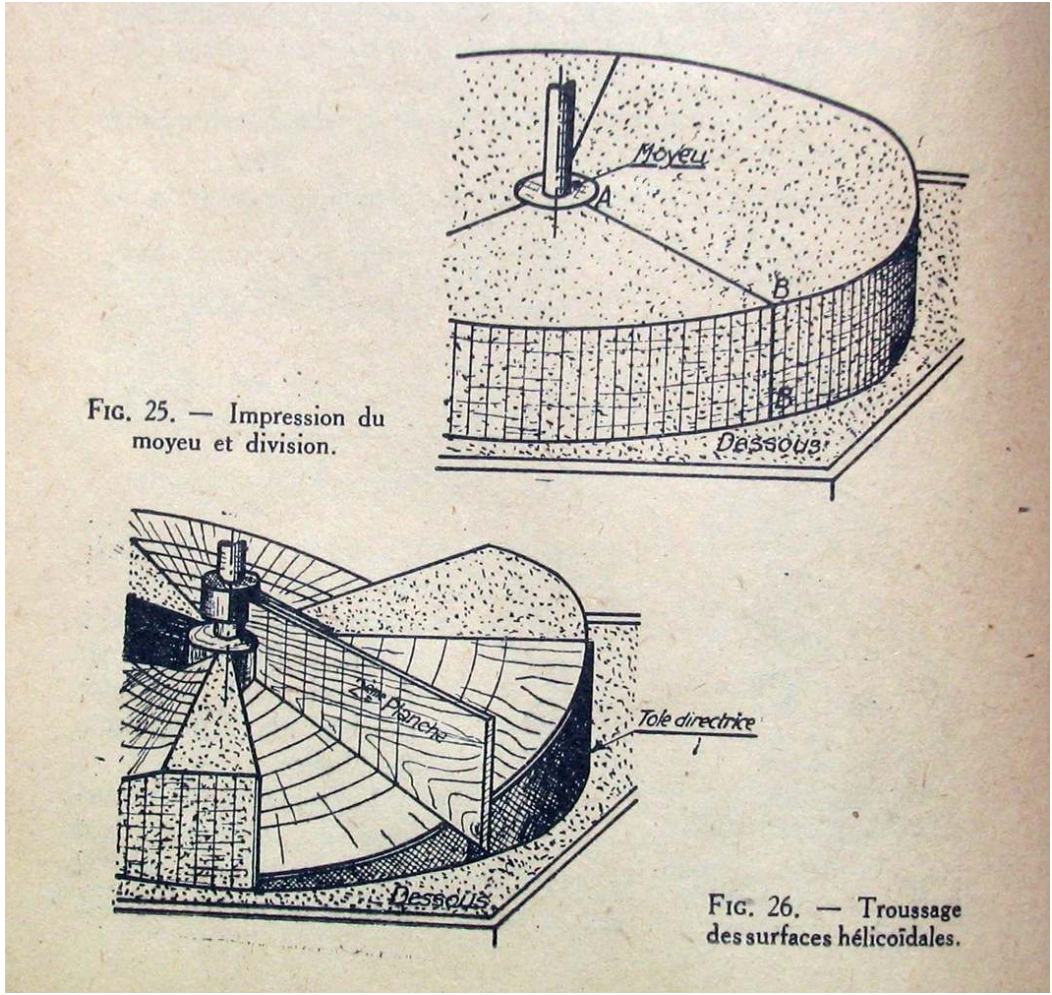

Les étapes du troussage du moule pour une hélice monobloc : «Impression du moyeu et division » ; «troussage des surfaces hélicoïdales ». NICOLET, André et alii. LE MODELEUR-MÉcANICIEN. Paris : Eyrolles, 1949, p. 342 


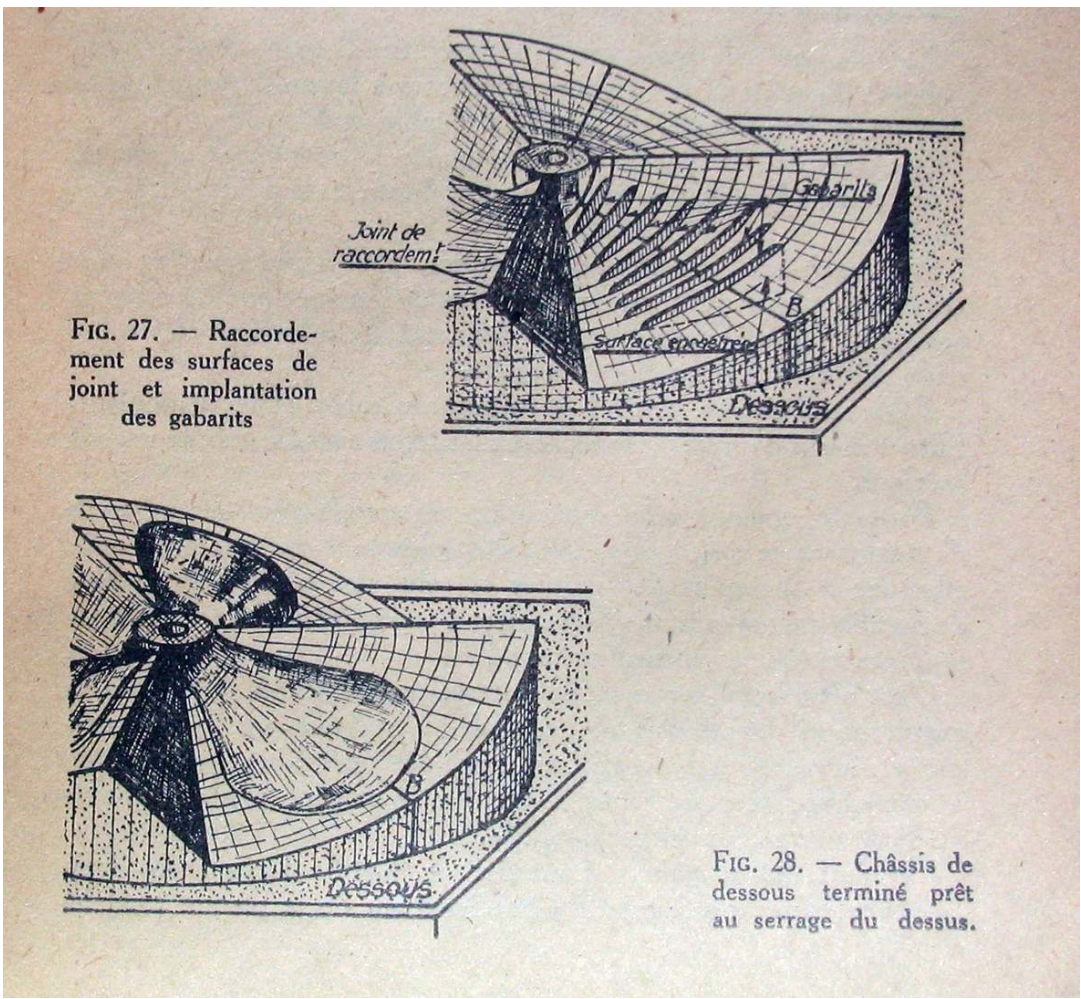

Les étapes du troussage du moule pour une hélice monobloc : «Raccordement des surfaces de joint et implantation des gabarits [de section] »; "Châssis de dessous terminé prêt au serrage du dessus ». NICOLET, André et alii. LE MODELEUR-MÉCANICIEN. Paris : Eyrolles, 1949, p. 343. 


\section{Figure 27}

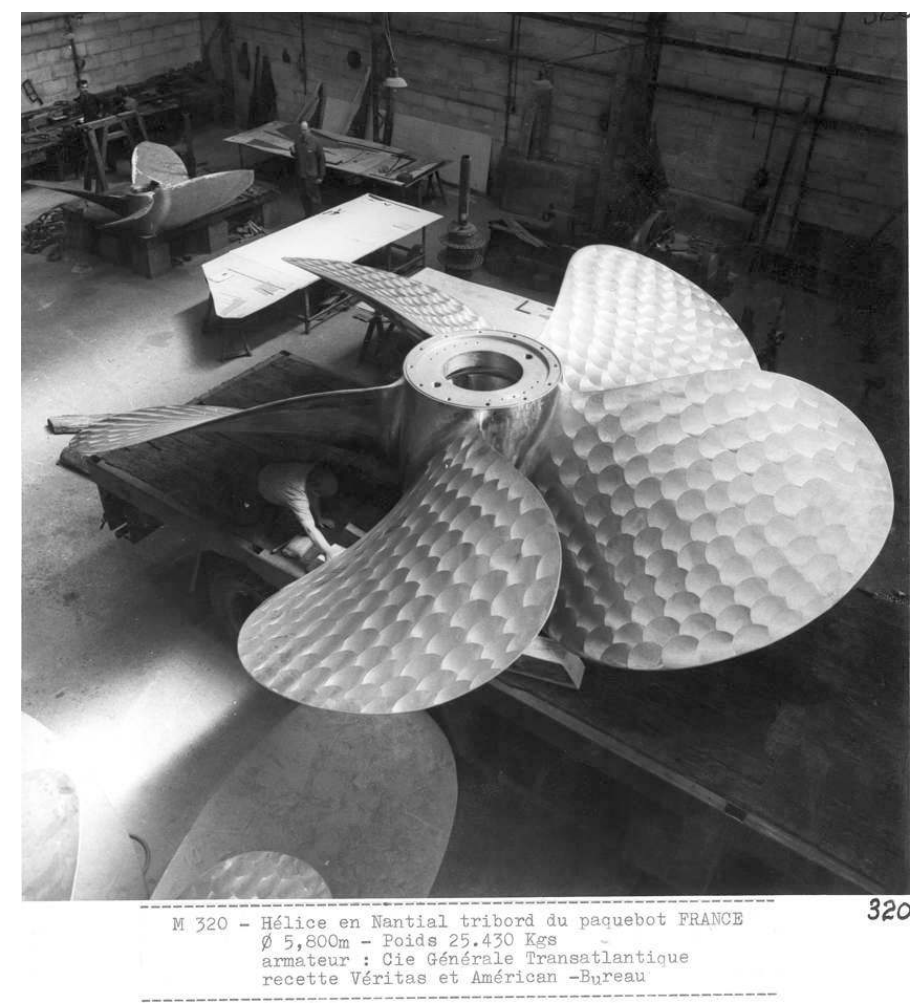

Une des hélices du France prête à la livraison : diamètre 5,80 m, poids 25430 kg, Photographie, vers 1960. Dossier photographique Fonderies de l'Atlantique, Archives association Histoire de la Navale à Nantes.

(c) AHNN 
Figure 28

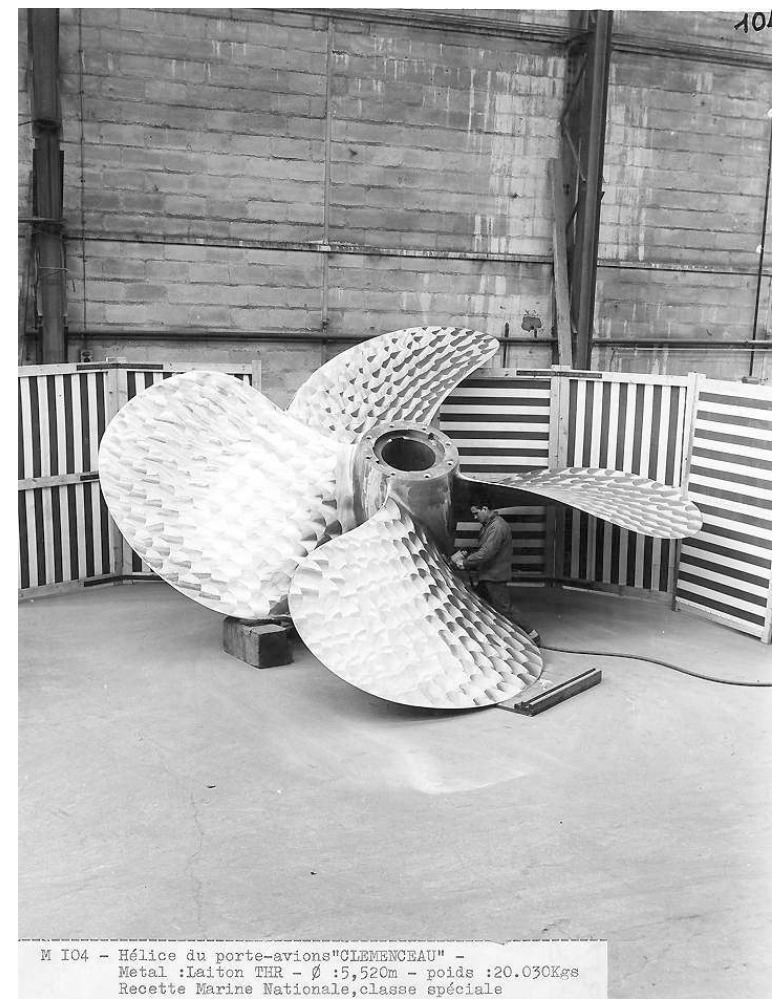

Une des hélices du porte-avions Clemenceau en cours de finition : diamètre 5,52 m, poids $20030 \mathrm{~kg}$ Photographie, vers 1960. Dossier photographique Fonderies de l'Atlantique, Archives association Histoire de la Navale à Nantes.

(c) AHNN

\section{Qu'est-ce qu'une hélice?}




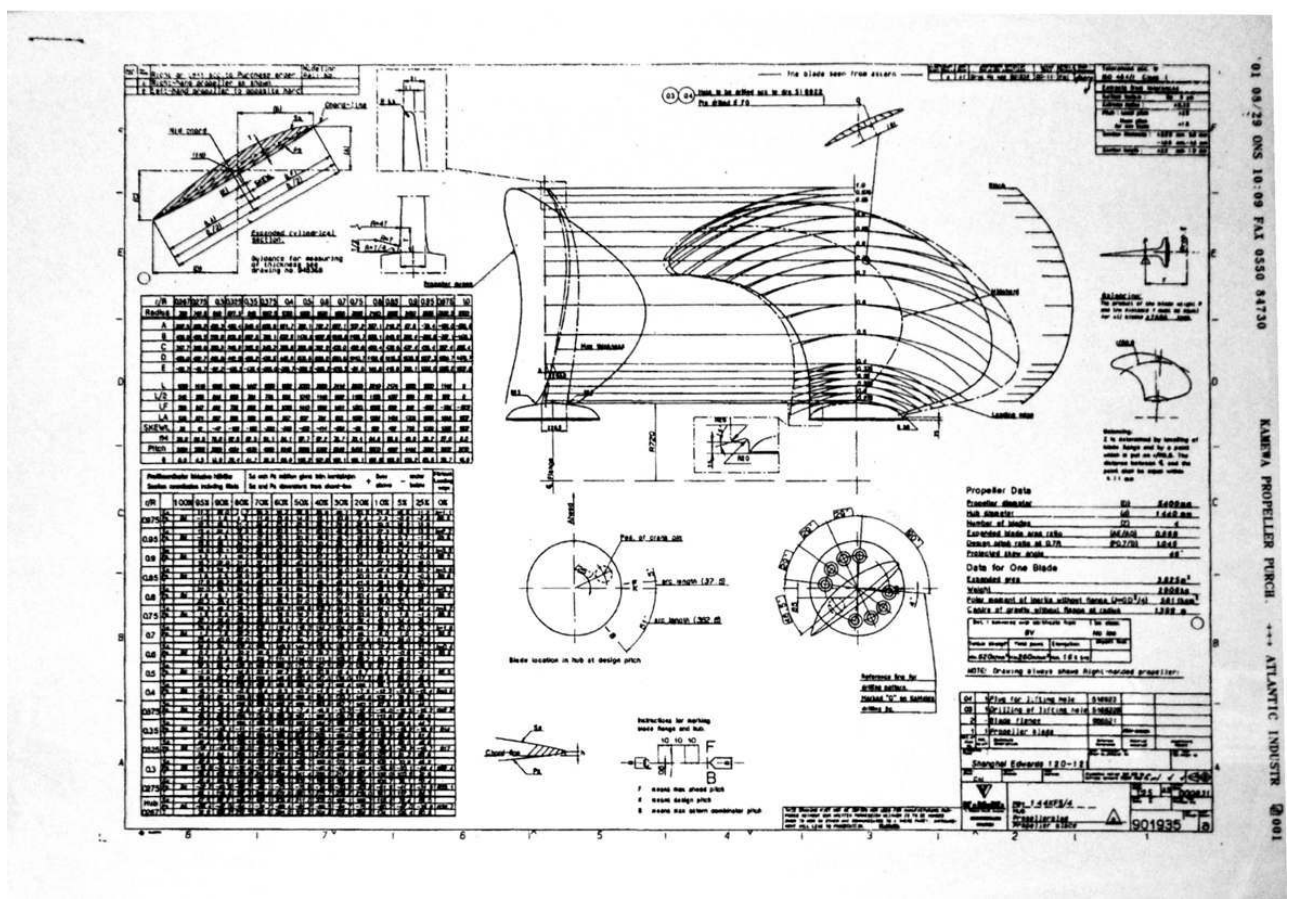

Un exemple de commande aux Fonderies de l'Atlantique en 2001 : le modèle pour Kamewa (commande 901 935) correspond à une hélice à quatre pales, avec 5,40 m de diamètre, il s'agit d'une grande dimension. Document Atlantic industrie. La commande correspond en fait à deux hélices sur ce type de grand navire à double propulseur, hélice à pas à droite et hélice à pas gauche.

(c) Archives Atlantic Industrie.

16 L'ensemble groupe-propulseur du navire est constitué du moteur, de l'arbre et de l'hélice portée en son extrémité. Une commande aux fonderies, c'est sans doute un dessin, mais c'est d'abord un ensemble de cotes rigoureuses correspondant au projet du navire. Pour les grands bâtiments, la commande recouvre deux types de modèles, pas à droite et pas à gauche, soit la paire d'hélices disposées symétriquement à l'arrière (fig. $\left.\mathbf{n}^{\circ} 29\right)$. Pour certains modèles, le projet peut correspondre à des séries de navires et permettra donc la coulée d'un nombre important de pales. Il s'agit maintenant pour ce type de coulées d'hélices à pales orientables qui permettent une régulation de la marche; elles sont presque systématiquement utilisées dans la marine civile. En France, la marine nationale commande beaucoup d'hélices monoblocs, c'est le cas des hélices de sous-marins nucléaires, avec un grand nombre de pales pour limiter les nuisances sonores, et de celles du porte-avions Charles de Gaulle (hélices à cinq pales).

Les hélices marines se composent d'un moyeu monté sur l'arbre porte-hélice et de plusieurs ailes, la plupart du temps trois ou quatre disposées régulièrement autour du moyeu. C'est la «face poussante » des ailes qui est dirigée vers l'arrière, le « dos » de chaque aile est donc dirigée vers l'avant du navire ${ }^{13}$. Le principe de l'hélice est de définir une succession de cylindres formé par le mouvement concentrique à l'axe de l'hélice. Le développé de ces cylindres est appelé "profil sustentateur». La face poussante est dessinée sur une surface engendrée par une courbe qui s'appuie par un mouvement en hélice d'une droite généralement perpendiculaire à l'axe, ou légèrement inclinée vers l'arrière : il s'agit d'une surface hélicoïdale, définie par un « pas » $\left(\right.$ fig. $\left.\mathbf{n}^{\circ} \mathbf{3 0}, \mathbf{n}^{\circ} \mathbf{3 1}\right)$. 
Figure 30

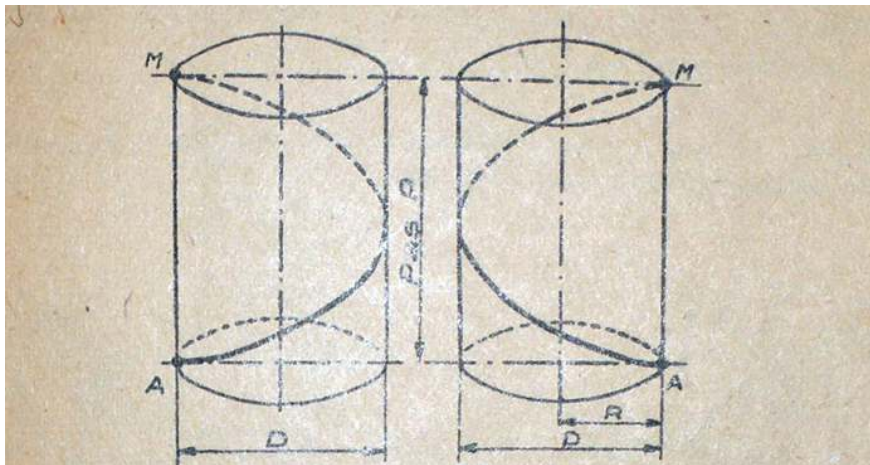

Fic. 1, - Helice à droite, FIG. 2, - Hélice à gauche

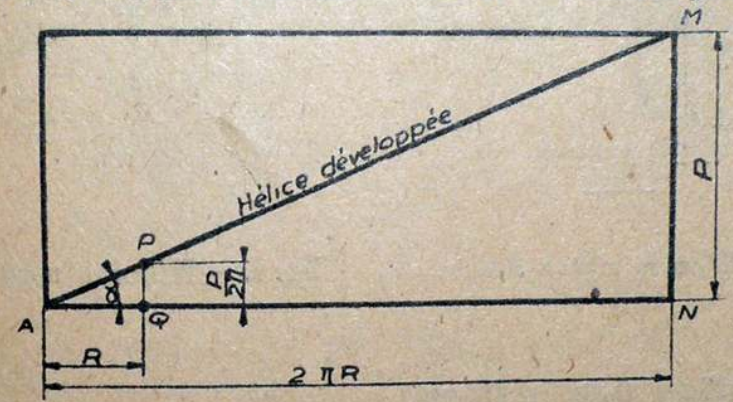

Fic. 3. - Développement de l'hélice.

Schéma de principe du pas d'une hélice. NICOLET, André et alii. LE MODELEUR-MÉCANICIEN. Paris : Eyrolles, 1949, p. 327. 


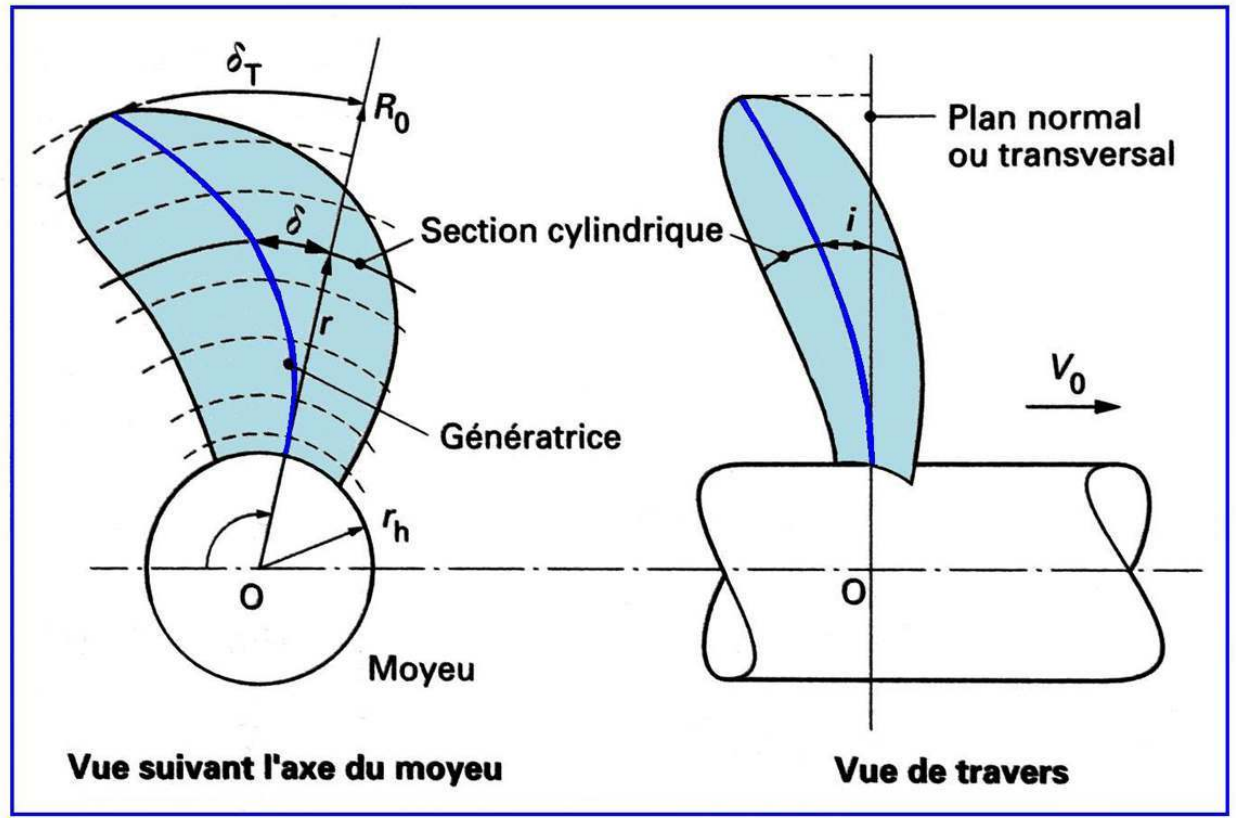

Figure 1 - Forme générale d'une hélice

Forme générale d'une hélice. AUCHER, Max. "Hélices marines 》, TECHNIQUES DE L'INgÉNIEUR - B 4360, 1996, p. 4.

Les hélices peuvent être à pas variable suivant la variation ou non du pas de l'arête d'attaque à l'arête de sortie, ou suivant le rayon. D'un point de vue dynamique, la théorie de l'hélice s'apparente à celle de l'aile portante en aérodynamique mais doit s'accorder de manière plus complexe, compte tenu des interactions entre les pales et des phénomènes de tourbillonnement de l'écoulement derrière l'hélice. Pour simplifier, on peut dire que l'hélice émet par réaction une force propulsive donnée par l'équation d'Euler $F=Q\left(V_{2}-V_{1}\right)$ où $\mathrm{Q}$ est le débit des filets d'eau la traversant (en $\mathrm{kg} / \mathrm{s}$ ) et $\mathrm{V}_{1}$ et $\mathrm{V}_{2}$, respectivement la vitesse du navire et la vitesse en aval de l'hélice. C'est la rotation des pales qui fournit une puissance d'accélération aux filets d'eau. La pale d'hélice se comporte comme un profil : l'inclinaison de chaque pale permet de créer une force de portance grâce à l'interaction filets d'eau/profil, en fonction de la vitesse de défilement, composante de la vitesse linéaire et de la vitesse de rotation (fig. $n^{\circ} 32, n^{\circ} 33$ ). 


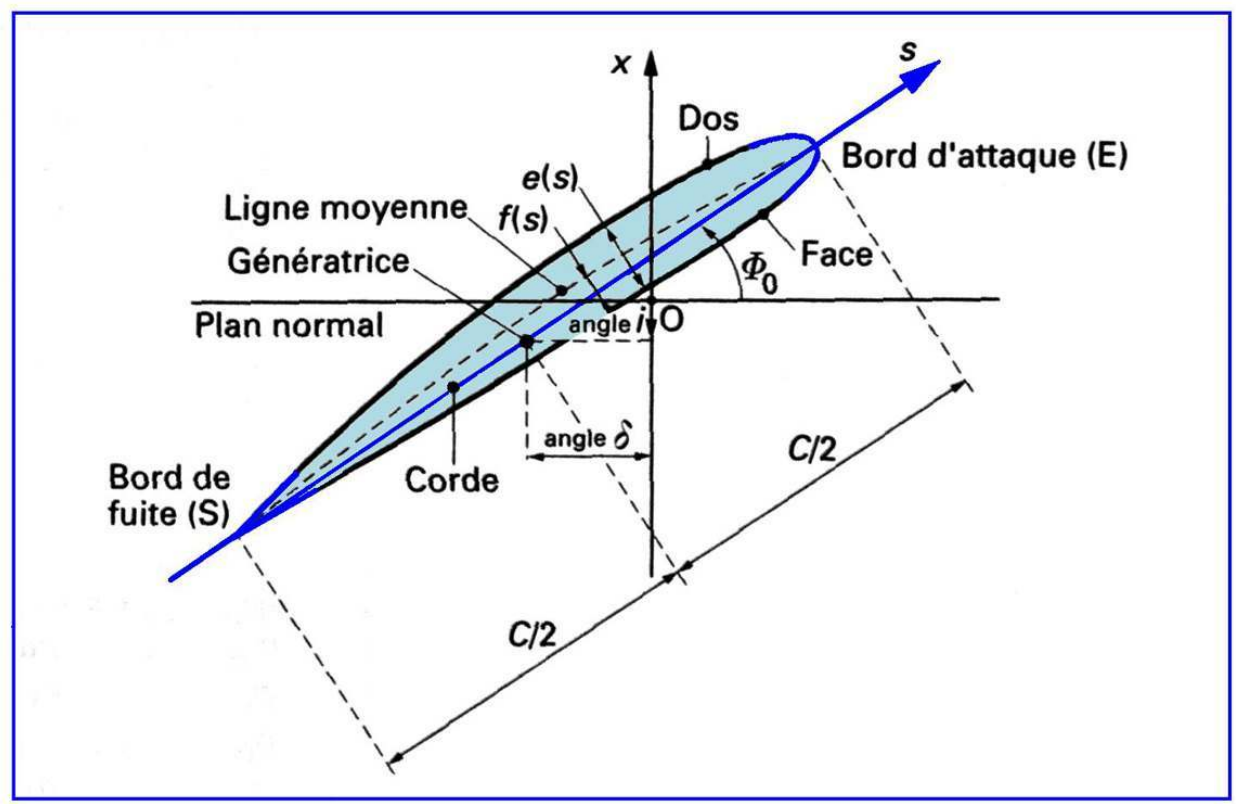

\section{Figure 2 - Définition de la géométrie d'une pale}

Définition de la géométrie d'une pale. AUCHER, Max. « Hélices marines », TECHNIQUES DE L'INgÉNIEUR - B 4360, 1996, p. 4.

Figure 33

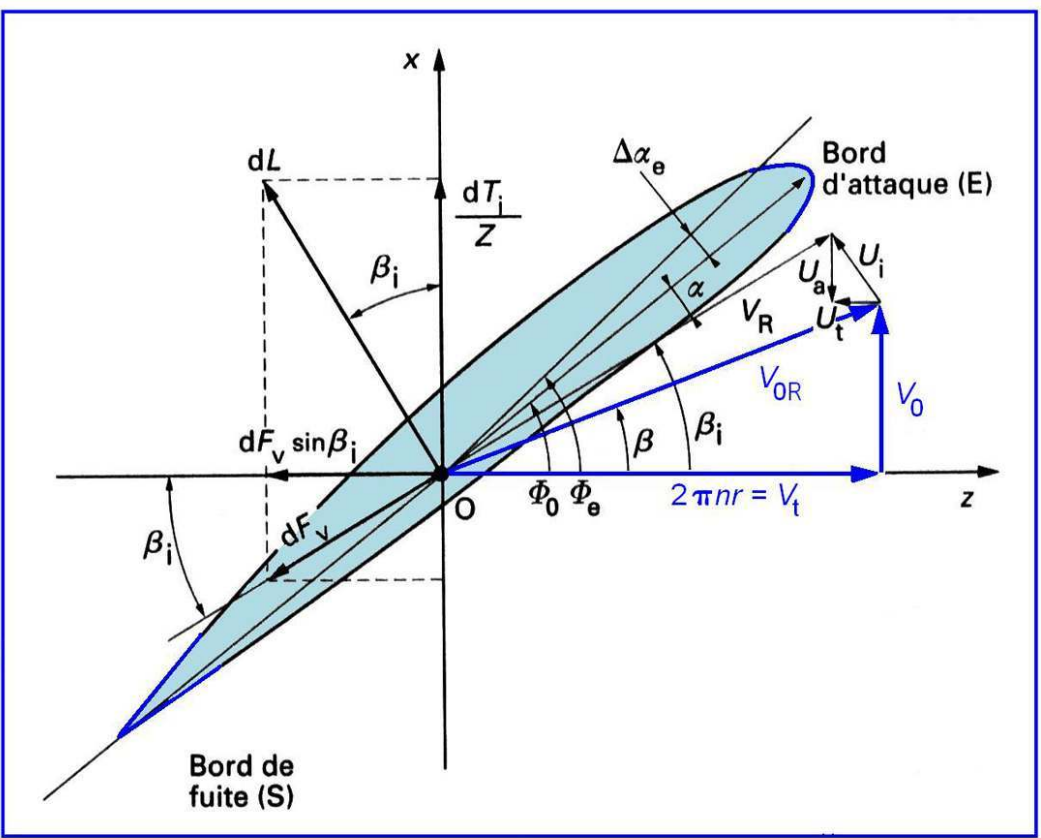

Figure 4 - Définitions des différentes grandeurs intervenant dans le fonctionnement hydrodynamique d'une section de pale

Définition des différentes grandeurs intervenant dans le fonctionnement hydrodynamique d'une section de pale. AUCHER, Max. "Hélices marines », TECHNIQUES DE L'INgÉNIEUR - B 4360, 1996, p. 5. 
Les hélices sont ainsi définies à partir du projet du navire, bâtiment de surface ou sousmarin, et en fonction de son déplacement, de la vitesse escomptée et donc de la puissance propulsive nécessaire, en tenant compte d'un certain niveau de bruit et de vibrations. On définit ensuite en conséquence les caractéristiques principales de l'hélice : diamètre total et diamètre du moyeu, nombre et dessin des pales, vitesse de rotation ${ }^{14}$. Les premiers calculs estimatifs permettent d'obtenir un diamètre d'hélice en fonction de la puissance en sortie d'arbre et la vitesse de rotation. De fait, plusieurs types de calcul permettent les estimations successives. Retenons ici les grandes lignes du projet de navire depuis les données initiales déjà évoquées, ou des données d'essais sur des modèles préexistants. En fonction principalement de la vitesse, de la puissance absorbée et du nombre de tours, on obtient une première approximation. L'hélice "optimale ", pour laquelle on a déterminé le diamètre et le nombre de pales, c'est-à-dire aussi la surface développée des pales, est ensuite confrontée à de nouveaux calculs concernant le couple hélice/moteur. On peut alors se reporter à l'avant-projet du navire puis faire des retouches et des modifications éventuelles plus ou moins fines: formes des profils, frottement des pales, dévers ou cambrures, pressions sur les pales, réglage des zones de cavitation ${ }^{15}$

\section{C'est donc bien d'un objet uniquement issu du calcul qu'il s'agit dans cette production industrielle}

Si la littérature est assez abondante sur la question théorique du calcul, elle est moins prolixe en ce qui concerne la fabrication elle-même et la fonderie en particulier. L'article de Max Aucher dans les Techniques de l'Ingénieur, ne consacre que deux pages au sujet en renvoyant aux connaissances extérieures en terme de fonderie des alliages mais en n'abordant qu'à peine la spécificité réelle de cette production ${ }^{16}$. C'est plutôt dans la littérature spécialisée en fonderie qu'on trouve quelques références ${ }^{17}$ mais c'est paradoxalement dans les ouvrages pratiques, destinés davantage aux ouvriers qu'à la maitrise, que l'on trouve les meilleures explications sur cette technique désormais abandonnée qu'est le troussage des hélices ${ }^{18}$. Ce faisant, on passe à d'autres types de connaissances et de pratiques, d'autres compétences. Si l'ingénieur sait calculer dans son projet de navire le galbe de l'hélice, il faut bien, par un autre type de savoir, le transcrire dans la forme. Savoir et savoir-faire se cumulent alors non plus seulement pour projeter le monde (ce qui serait du domaine du scientifique, ici relayé par l'ingénieur) mais pour le fabriquer (ce qui serait du domaine du technicien, à qui, ici encore, mais d'une manière différente, l'ingénieur passe le relais), avec les assemblages de bois, le travail du menuisier et de sa gouge (fig. $\mathbf{n}^{\circ} \mathbf{3 4}, \mathbf{n}^{\circ} \mathbf{3 5}$ ), et puis un peu plus tard, les incursions douces du modeleur dans le sable dur de la fonderie. 
Figure 34

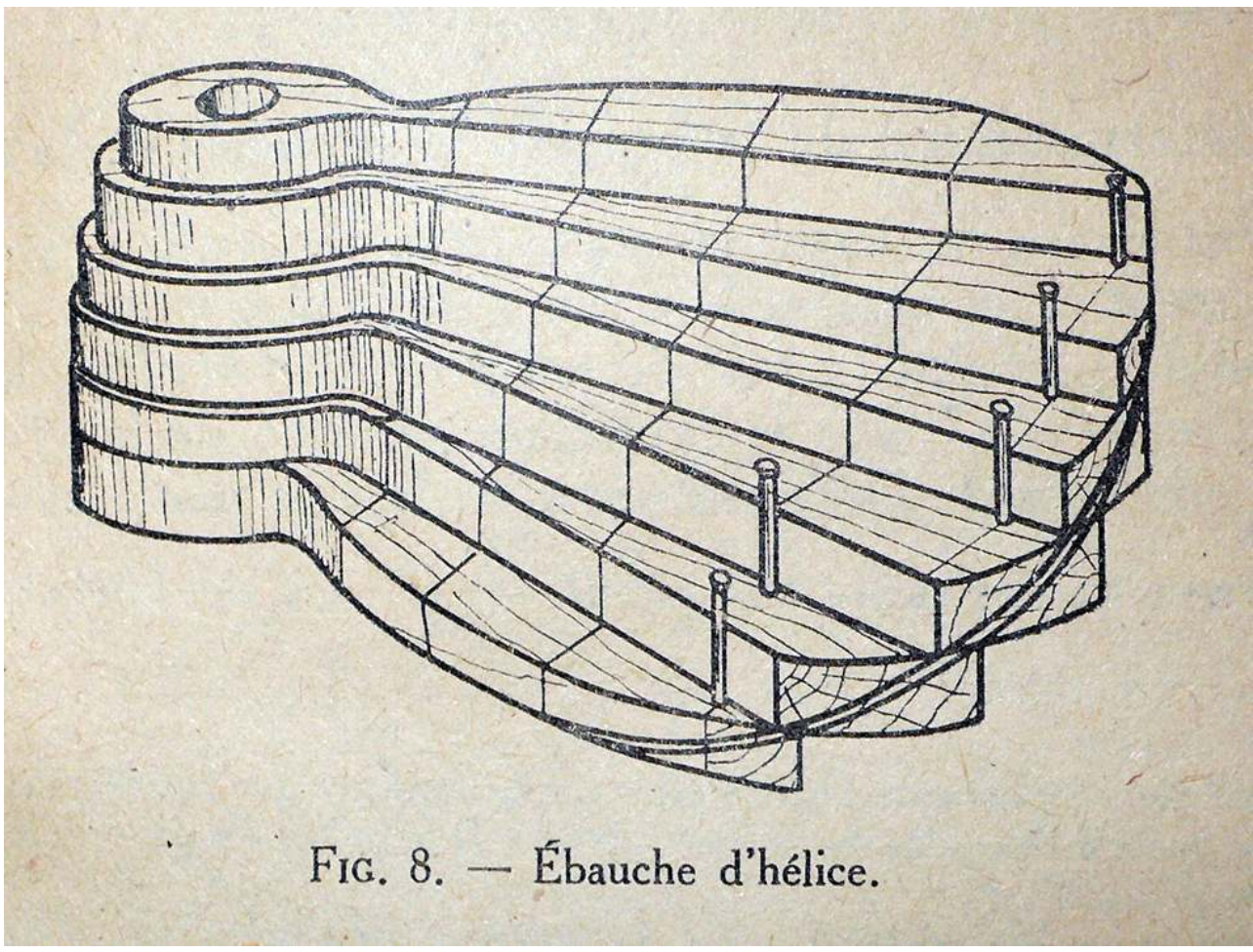

La réalisation d'un modèle d'hélice, une pale avec son moyeu permettra la réalisation du moule par rotation successive du modèle en fonction du nombre de pales projeté : "Ébauche d'hélice », NICOLET, André et alii. LE MOdeleUR-MÉCANicien. Paris : Eyrolles, 1949, p. 343. 


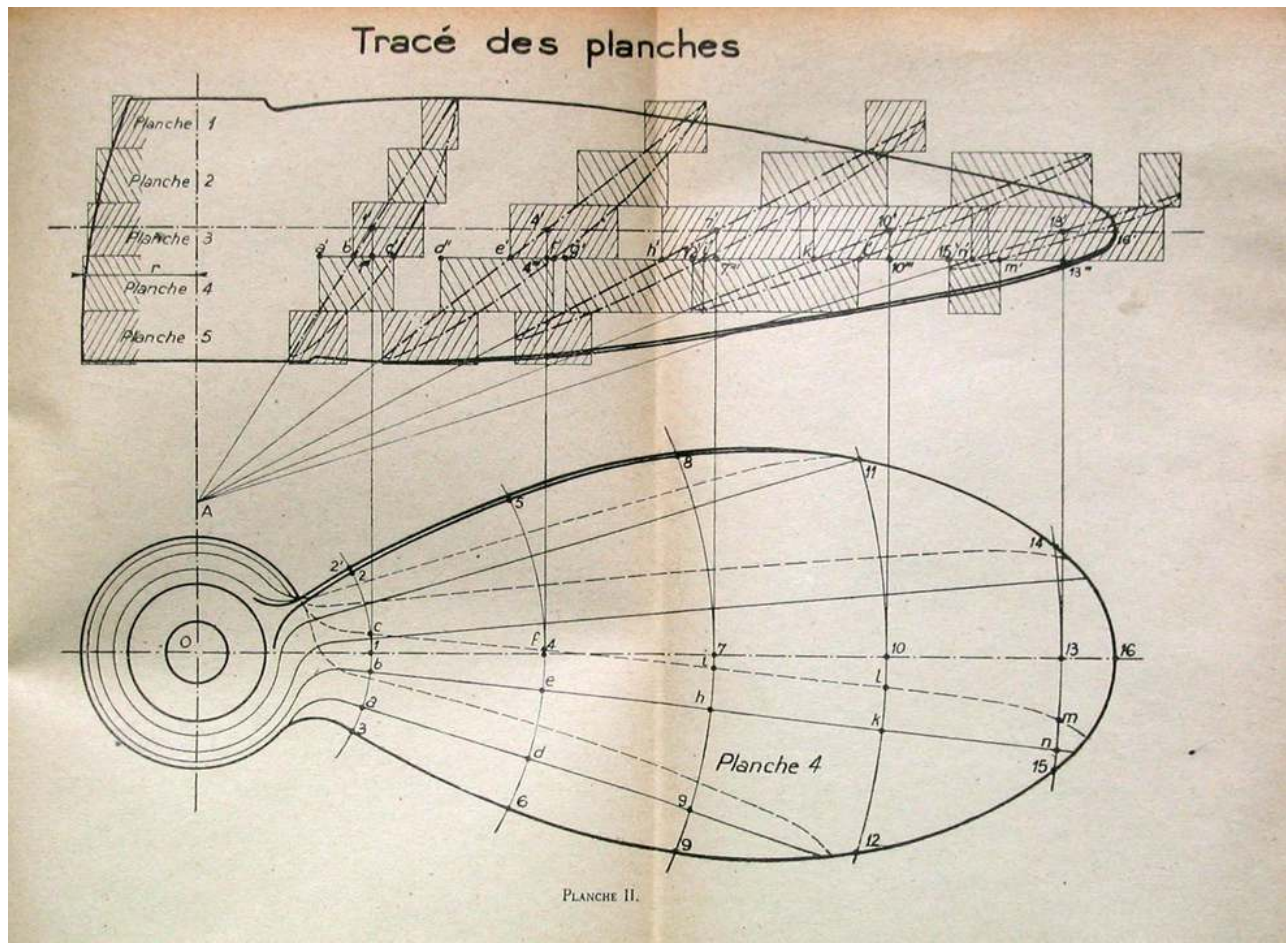

La réalisation d'un modèle d'hélice : «tracé des planches », NICOLET, André et alii. LE MODELEURMÉCANICIEN. Paris : Eyrolles, 1949, p. 343.

(c) Jean-Louis Kerouanton.

Qu'en est-il aujourd'hui ? On aura compris que l'enquête documentaire est à poursuivre et qu'il faut encore procéder à des dépouillements et établir des comparaisons systématiques. Malgré quelques incidents vers 2005 avec des actes de vandalisme et des vols dans un local pourtant sécurisé, la collection est désormais en lieu sûr. Telle quelle, elle porte témoignage non seulement du calcul mais aussi du travail technique. Comment comprendre sinon, les marques, les repères, les inscriptions en millimètres ou encore les plaques apparemment incohérentes quand elles sont rapportées sur ces objets dont on vient de dire la perfection. C'est qu'en fait, la fonderie n'est pour le coup pas une science exacte et si tel modèle relève de la fidélité au calcul, sa réalisation après la coulée peut s'avérer difficile à finir. Au contrôle des cotes, on anticipera l'écart entre le modèle et la réalisation finale toutes les indications successives de cote sur le modèle lui-même témoignent de ce travail minutieux de finition, des indications de surépaisseur que le meuleur devra travailler savamment pour arriver à la commande d'origine. 


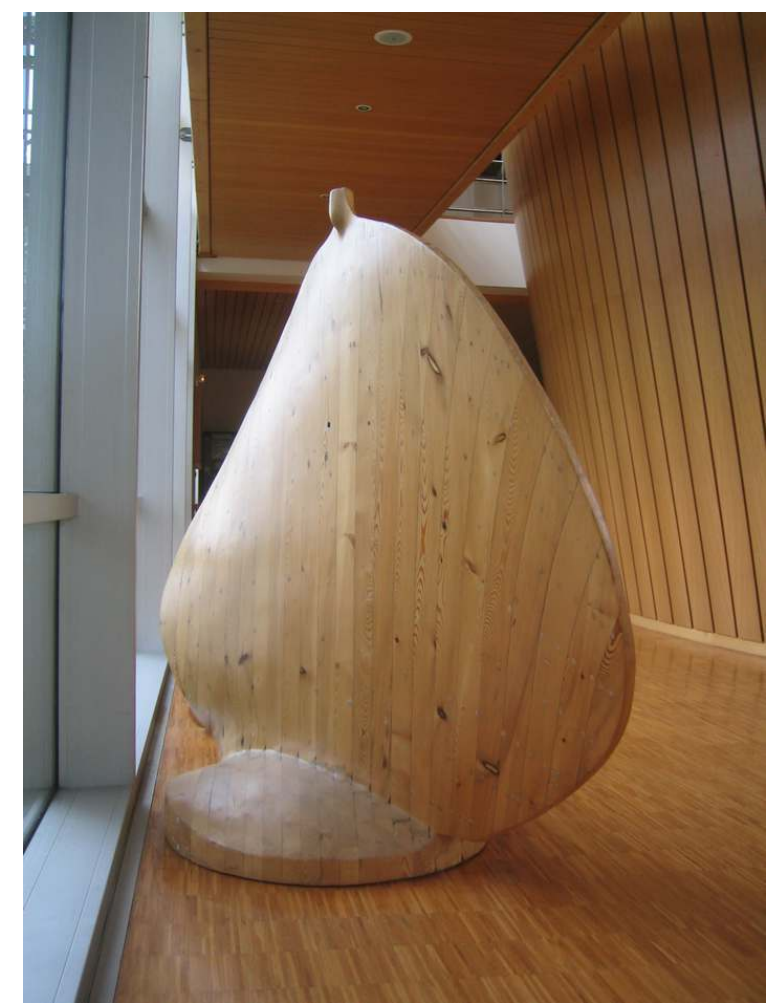

L'École supérieure du bois de Nantes conserve quelques modèles de pales et d'hélices récupérés peu de temps avant le déménagement d'Atlantic Industrie. Ici on ne parle que du bois, plus d'épaisseur ni d'inscriptions techniques, juste la beauté et les courbes d'un assemblage mais plus d'information non plus du point de vue de l'histoire du modèle et de son usage. Photo Jean-Louis Kerouanton, juin 2005.

Si le meuleur lui-même estime qu'il n'aura pas assez de matière, alors il fait rajouter tel « placard » sur la pièce, pour avoir la main et travailler à son aise une fois l'objet coulé. On comprend bien combien le modèle lui-même devient ainsi véritablement un document sur lui-même. Comment juger alors les récupérations de l'École supérieure du bois à Nantes qui, en retrouvant le bel aspect du bois ont sans doute sauvé de la destruction totale certains modèles mais en ont supprimé toutes les informations techniques (fig. $\mathbf{n}$ -36)?

Certains experts ne s'y sont pas trompés. Sollicités par les services de la DRAC des Pays de la Loire en 2005, ils étaient unanimes à saluer l'intérêt de l'ensemble "probablement unique " où chaque modèle "représente un "chef-d'œuvre", au sens de l'accomplissement d'un savoir-faire de modeleur qu'il convient de restituer ${ }^{19}$ », « une collection dont a du mal à imaginer qu'elle existe avec une telle ampleur et une telle force de témoignage ", pour laquelle "toutes les qualités nécessaires à la valorisation sont réunies ici : force du témoignage, authenticité, pertinence totale de la localisation, lien entre passé et présent, valeur symbolique, monumentalisme, effet de série, qualités esthétiques propres des objets ${ }^{20} »$. Des objets enfin dont le rapport au calcul ne manque pas d' être souligné : «chaque modèle est la représentation volumique d'une équation mathématique... L'hélice est à la fois un volume complexe chargé d'assurer la propulsion d'un navire, sa forme est le résultat d'un calcul tenant compte de la puissance du moteur, de la structure du navire et de son usage. À ce titre, la collection relève du patrimoine scientifique. Parmi les objets de représentation scientifique, les objets de représentation 
de formes géométriques ou mathématiques sont plutôt rares et le plus souvent liés à l'enseignement des mathématiques ou des sciences ${ }^{21}$ ”.

Figure 37

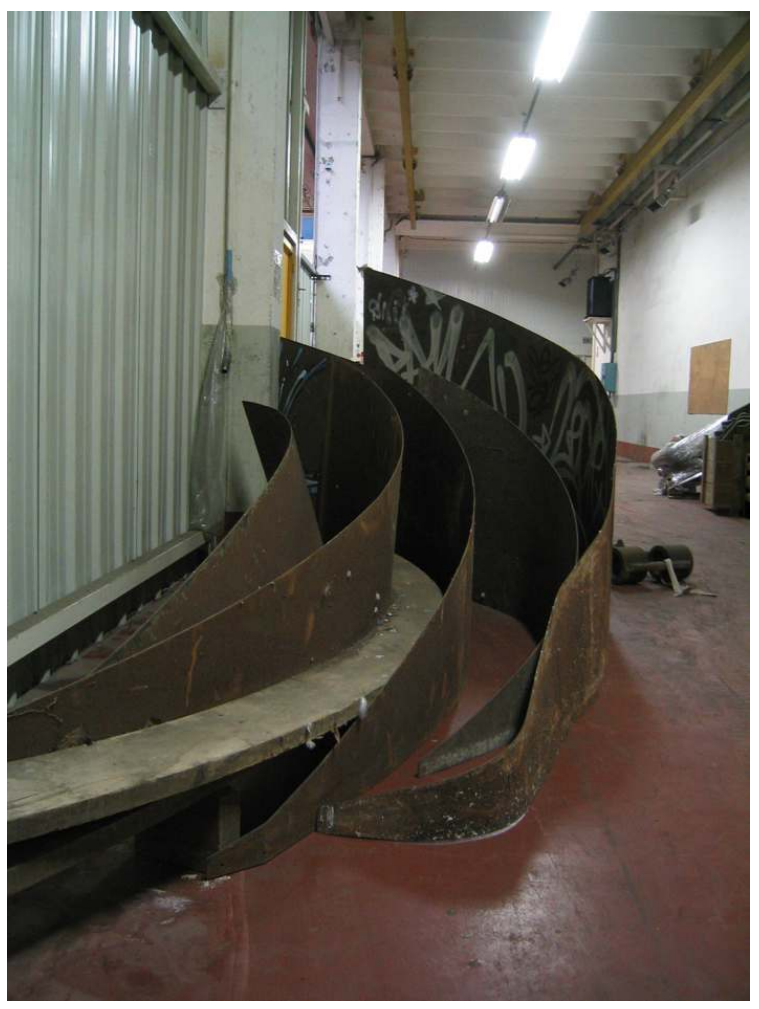

Des éléments du troussage de moule d'hélices en fosse, les gabarits de direction. Stockage actuel de la collection des objets des anciennes Fonderies de I'Atlantique, ancienne usine Alstom, Nantes. Photo Jean-Louis Kerouanton, 2005.

(c) Jean-Louis Kerouanton. 
Figure 38

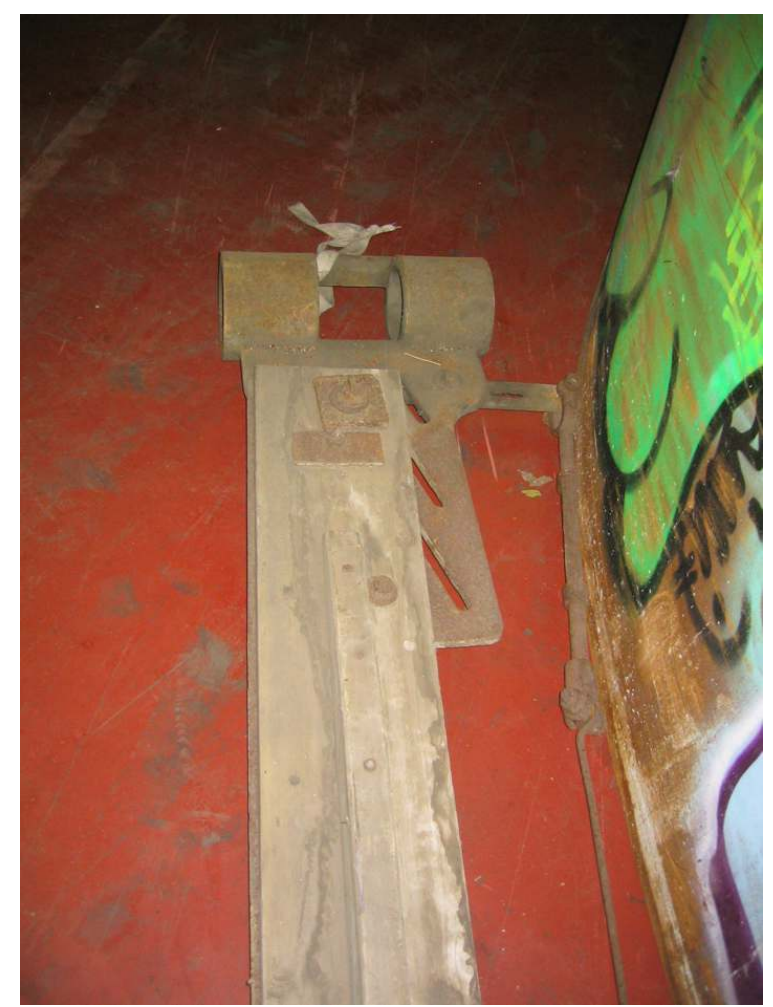

Une planche à trousser, détail sur le trusquin, fixation de la planche et positionnement de l'axe de rotation. Stockage actuel de la collection des objets des anciennes Fonderies de l'Atlantique, ancienne usine Alstom, Nantes. Photo Jean-Louis Kerouanton, 2005.

(c) Jean-Louis Kerouanton.

On l'aura compris, cette belle collection dort, en attente d'une valorisation à définir (fig. $\mathbf{n}^{\circ} \mathbf{3 7}, \mathbf{3 8}, \mathbf{3 9}, \mathbf{4 0}$ ) ; elle est bien le témoignage non seulement d'un élément parmi d'autres de l'histoire de la navale mais, de manière privilégiée et monumentale, des rapports étroits qu'ont entretenus les sciences et les techniques dans le cadre d'un projet industriel. Qu'il nous soit permis, avec d'autres, de souhaiter son intégration dans les projets de valorisation future de l'île de Nantes. 
Figure 39

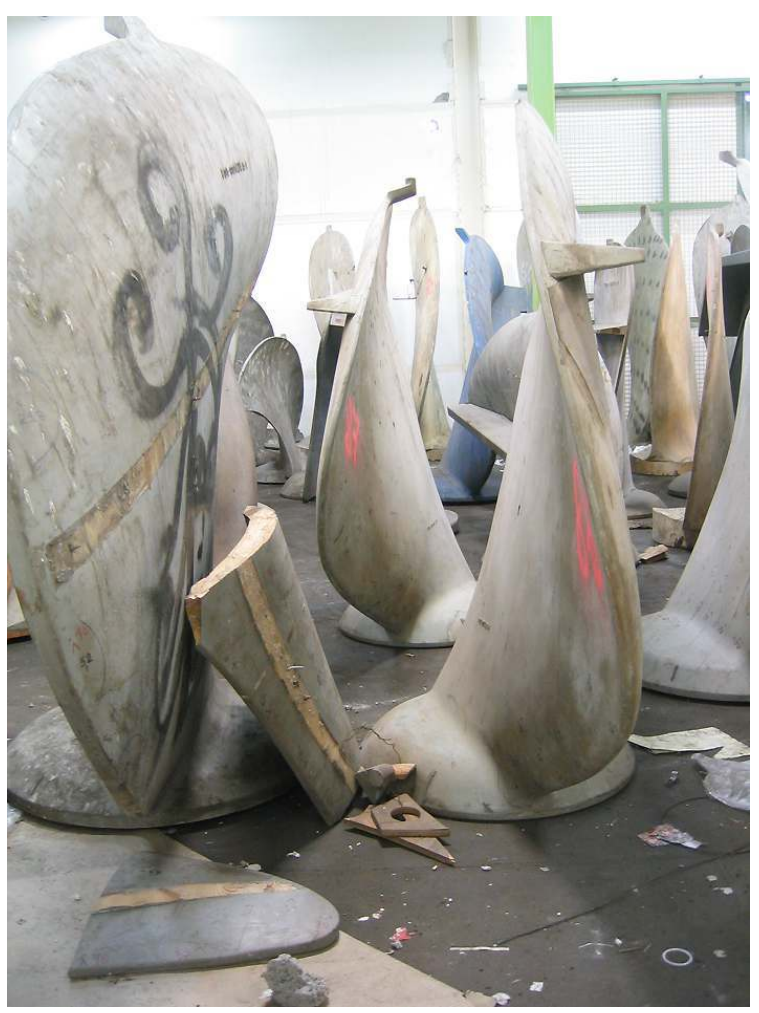

Les modèles de pales d'hélices. Stockage actuel de la collection des objets des anciennes Fonderies de l'Atlantique, ancienne usine Alstom, Nantes. Photo Jean-Louis Kerouanton, 2005.

(c) Jean-Louis Kerouanton. 


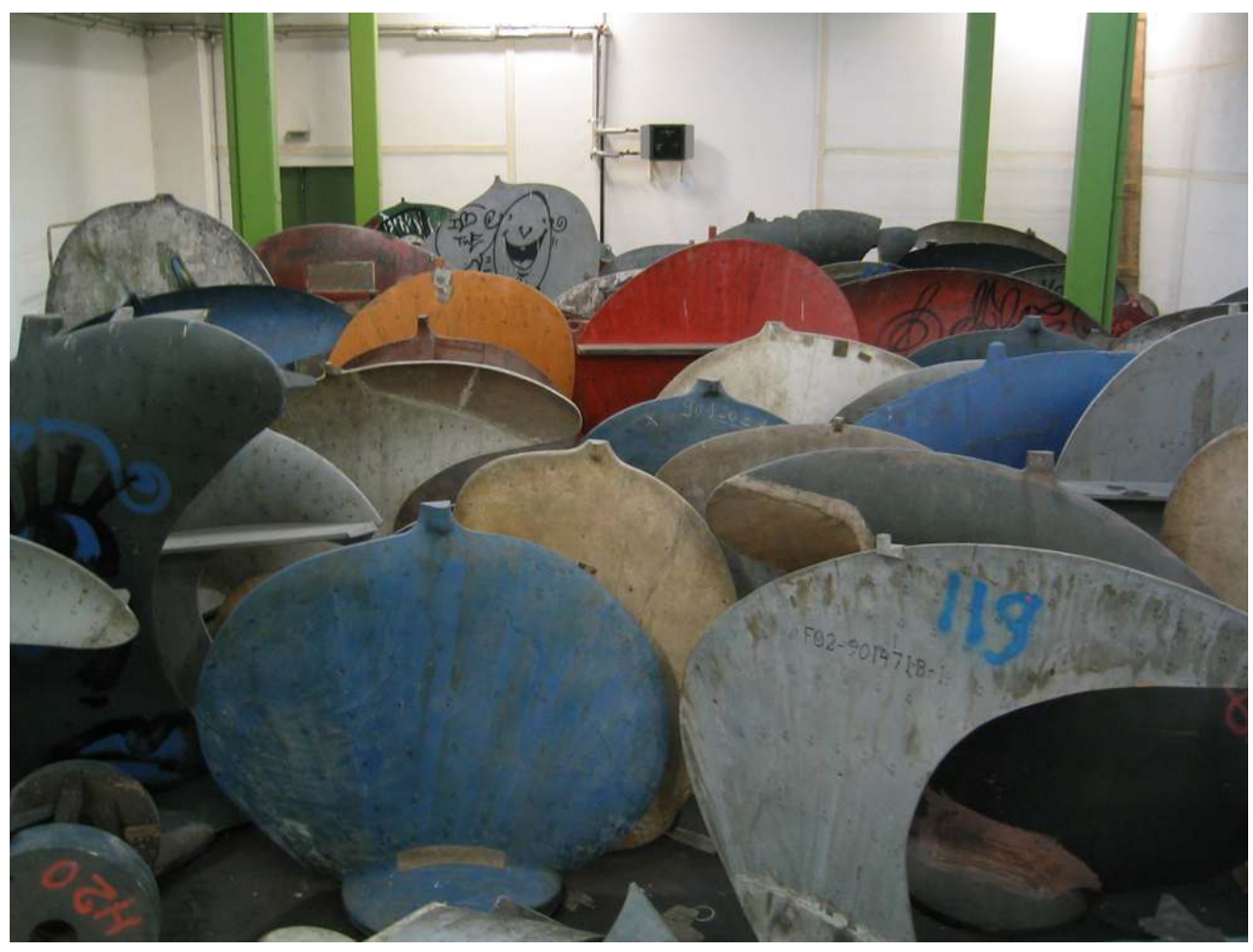

Vue d'ensemble du stockage actuel de la collection des objets des anciennes Fonderies de l'Atlantique, ancienne usine Alstom, Nantes. Photo Jean-Louis Kerouanton, 2005.

(c) Jean-Louis Kerouanton.

\section{NOTES}

1. KEROUANTON, Catherine. Communauté urbaine de Nantes Mission Île de Nantes. Récolement des objets industriels des anciennes Fonderies de l'Atlantique 13 boulevard Vincent Gâche. Synthèse technique et iconographique. Rapport de recherche, octobre 2001. Voir également : KEROUANTON, Catherine. La collection des modèles d'hélice des anciennes Fonderies de l'Atlantique, L'archéologie industrielle en France, $n^{\circ}$ 41, décembre 2002, p. 66-69. Parallèlement, une mission de relevés des fours était commandée à l'architecte Pascal Filâtre en janvier 2002.

2. KEROUANTON, Jean-Louis. Usine des îles, usines de Loire. Cas de figures à Nantes, L'archéologie industrielle en France, $n^{\circ}$ 41, décembre 2002, p. 14-22, sur les Fonderies p. 18-19. 3. de GRAVELAINE, Frédérique. A Nantes, la mutation d'une île. Les chroniques de l'île - 1. Nantes : Place publique, 2009, p. 31-32, qui reprend en quelques lignes ce jeu d'acteur de l'époque. 4. Pour de premières indications voir : KEROUANTON, Catherine. Communauté urbaine de Nantes Mission île de Nantes. Récolement des objets industriels des anciennes Fonderies de l'Atlantique 13 boulevard Vincent Gâche. Synthèse technique et iconographique. Rapport de recherche, octobre 2001. L'entreprise dispose encore elle-même d'un fonds d'archives important qui reste à exploiter même si un incendie en 2000 avait détruit certains papiers. Aux archives 
départementales de Loire-Atlantique, dossier d'entreprise dans les fonds des bâtiments dangereux et insalubres (ADLA 1M 1496, 1503) mais surtout dans les fonds de la reconstruction qui conservent l'essentiel des autorisations plus anciennes (ADLA 187 W 51 à 53), suite aux bombardements.

5. Sur Louis Babin-Chevaye: ROCHCONGAR, Yves. Capitaines d'industrie à Nantes au XIXe siècle : Nantes: MeMO, EPI, 2003, p. 119-121. Voir également FIERAIN, Jacques. Continuités familiales et ruptures dans la construction navale nantaise, Enquêtes et documents, XVII, Nantes : université de Nantes, 1990, p. 143-162.

6. La «Boire Toussaint» est un des petits bras de Loire qui scindaient en plusieurs parties les différentes langues de terre que constituaient les îles de la Loire à l'époque entre les deux rives principales avec le centre historique de Nantes au nord et Rezé au sud. La conquête progressive des espaces va contribuer à boucher la totalité de ces boires pour arriver à la constitution d'une seule île au milieu du XXe siècle. Pendant longtemps, les Nantais garderont le nom des différentes îles pourtant réunies : la Prairie au Duc pour le site des chantiers navals par exemple. Ce n'est seulement qu'à la fin $\mathrm{du} \mathrm{XX}^{\mathrm{e}}$ siècle, et après les premières réflexions urbaines de Dominique Perrault et François Grether en 1995, que l'appellation «l'île de Nantes » est partagée par tous. LELIÈVRE, Françoise. De l'industrie sur la prairie, L'archéologie Industrielle en France, $n^{\circ} 41$, décembre 2002, p. 6-13; PEYON, Jean- Pierre. Mémoire de la construction navale à Nantes et projets d'aménagement : de la Prairie-au-Duc à l'île de Nantes, Congrès national des Sociétés savantes «Des villes, des ports : la mer, les hommes » $\left(n^{\circ} 124 ; 1999\right.$; Nantes), Paris : CTHS, 2001, p. 285-294.

7. Les bâtiments appartenant à la Ville sont passés le jour du rendu des clés en 2001 à la Communauté urbaine, tout nouvellement créée.

8. KEREZEON, Michel. Les Ateliers et Chantiers de Bretagne, 1895-1909-1968, un chantier naval nantais. Maulévrier: Hérault, 1995. Et plus généralement sur la construction navale locale : KEROUANTON, Jean-Louis, SICARD, Daniel et alii. La construction navale en Basse-Loire . Nantes: ADIG, 1992; ROCHCONGAR, Yves. Des navires et des hommes. De Nantes à SaintNazaire, deux mille ans de construction navale. Nantes: Maison des Hommes et des Techniques, 1999.

9. 150 years of Kamewa. 1849-1999. Stockholm: Boardwalk International, Kamewa, 1999. Aimablement communiqué par Mathilde Leroux. Sur les productions contemporaines voir sur internet http://www.rolls-royce.com/marine/products/propulsors/propellers/index.jsp

10. L'affaire avait fait grand bruit à l'époque. Les expertises n'ont d'ailleurs pas clarifié parfaitement les responsabilités des différents acteurs (Fonderies et DCN) dans la casse de l'hélice du nouveau porte-avions nucléaire (voir, entre autres, le rapport de la DGA de décembre 2000, «Enquête qualité relative aux hélices du porte-avions Charles de Gaulle »). Le marché a ensuite été coupé en deux avec la fourniture par l'américain Bird Johnson de deux hélices, aujourd'hui installées sur le navire. Deux nouvelles hélices ont également été fondues par Atlantic Industrie, c'est l'équipement de remplacement.

11. Je tiens tout particulièrement à remercier son directeur Grégory Debaest, dont l'accueil est toujours parfait, et Christian Quillet, qui était alors un des plus anciens ouvriers de l'entreprise ; c'est lui qui nous a donné les premières explications sur la technique du troussage pour les hélices monoblocs.

12. Ensemble de deux hélices ; dossier AI 1536, 1996, Majesty of the seas ; 901418A1 ; 1536 ; KMW ; inscription sur le modèle de pale F01901418A 1, dimensions: L, 270; H, 185; 1, 85 cm, bois assemblé peint ; gris et rose ; report d'épaisseur de fonderie, inscription supplémentaire : points de cote des écarts au plan (en mm). Voir KEROUANTON, Catherine. Communauté urbaine de Nantes Mission île de Nantes. Récolement des objets industriels des anciennes Fonderies de l'Atlantique 13 boulevard Vincent Gâche. Synthèse technique et iconographique. Rapport de recherche, octobre 2001. 
13. LEFOL, Jean. Hélices propulsives marines. Paris : Hermann et Cie, 1950, p. 8.

14. Remerciements les plus vifs à Jean-Claude Masson pour tous ses éclaircissements.

15. AUCHER, Max. Hélices marines, Techniques de l'ingénieur - B 4360, 1996. Sur le projet d'hélice, p. 28-30. Des calculs d'hélice, expliqués en trois pages et très facilement accessibles sur internet sur le site de la FAO: Economies financières et de carburant dans la pêche artisanale. Document technique sur les pêches 383, par J.D.K WILSON, 2003: annexe 4 «Méthode Crouch de calcul d'hélice », téléchargeable sur http://www.fao.org/DOCREP/005/ X0487F/X0487F00.HTM

16. AUCHER, Max. Hélices marines, Techniques de l'ingénieur - B 4360, 1996, p. 30-31. Il en va de même dans d'autres ouvrages, par exemple: GERR, Dave. Propeller Handbook. The Complete Reference for Choosing Installing and Understanding Boat Propellers, International Marine, 1989 - 2001 qui n'évoque pas du tout la fabrication mais donne une liste de fournisseurs, p. 145.

17. RAME, Paul. Fabrication des hélices marines, Fonderie, n² 291, juin 1970, p. 213-221 et juillet 1970, n² 292, p. 235-241.

18. NICOLET, André et Robert, BRODBECK, Georges. Le modeleur mécanicien. Technologie professionnelle à l'usage des ouvriers et apprentis, des candidats au C.A.P, des élèves des Cours professionnels, des Ecoles de Métiers, des Centres d'apprentissage, des collèges techniques, des sections techniques industrielles des collèges modernes, etc. Paris : Eyrolles, 1949. Remerciements à Béatrice Poulain, documentaliste à l'ENSAM Angers, pour m'avoir ouvert les réserves de la bibliothèque.

19. Denis Woronoff, université de Paris-I, mai 2005, dossier Fonderies de l'Atlantique, DRAC Pays de la Loire.

20. Michel Cotte, université de Nantes, juin 2006, dossier Fonderies de l'Atlantique, DRAC Pays de la Loire.

21. Jean Davoigneau, ministère de la Culture, septembre 2005, dossier Fonderies de l'Atlantique, DRAC Pays de la Loire.

\section{RÉSUMÉS}

La découverte, l'étude et la sauvegarde partielle des bâtiments des anciennes «Fonderies de l'Atlantique » à Nantes en 2001-2002 ont permis également de révéler puis de conserver une extraordinaire collection d'objets de fonderie au sable correspondant à la fabrication des hélices et des pales d'hélice pour les plus gros navires commerciaux et militaires. La technologie de fonderie d'alliage de cuivre pour les hélices avait été adoptée en 1937 dans l'entreprise. L'ensemble des modèles en bois de pales d'hélice est d'abord apparu comme une accumulation de sculptures monumentales particulièrement épurées. L'étude technologique plus fine montre cependant que cette "beauté » réelle ne correspond nullement à la volonté d'un artiste mais relève uniquement des calculs liés pour chaque production à un projet de navire. Et c'est seulement le calcul qui permet d'expliquer les réalisations d'hélices monoblocs par troussage, sans modèle aucun; il ne reste alors de traces que les outils du troussage. Il s'agit bien dès lors d'un patrimoine scientifique - la transposition matérielle d'un calcul mathématique - tout autant que d'un patrimoine technique et industriel. C'est cette particularité qui fait la grande originalité 
de l'ensemble conservé par la communauté urbaine, en attendant, nous l'espérons, une valorisation future.

In 2001 and 2002, the study and partial preservation of the buildings of the former Fonderies de l'Atlantic in Nantes also allowed for the preservation of a remarkable collection of objects related to the sand foundry casting carried out by this firm, specialised in propellers for major commercial and military vessels. The firm began to employ copper alloys in its foundry techniques from 1937. The collection of wooden models prepared for the casting of propellers appears, at first sight, as a remarkable accumulation of rather abstract monumental sculptures. More detailed technical study of these objects, however, shows that their undeniable aesthetic qualities resulted only from the calculations required by particular projects for particular vessels. And it was by calculation alone, without wooden models, that the firm was able to manufacture propellers in a single piece, by trussing techniques. In this case, the only surviving material traces today are the trussing tools. Here then is a scientific heritage, the material expression of mathematical calculations, which is at the same time a technical and industrial heritage. This is doubtless the originality of the collection held today by the Nantes local authorities, and which, we hope, will soon be displayed and interpreted for the general public.

\section{INDEX}

Mots-clés : hélice, hélice marine, pales d'hélice, groupe propulseur de navire, calcul, conservation, fonte au sable, fonderie d'alliage de cuivre (cupro-aluminum), modèles de fonderie, modèles d'hélices, projet industriel, sciences de l'ingénieur, patrimoine scientifique, patrimoine industriel, patrimoine maritime, Nantes, Fonderie de l'Atlantique

Keywords : propeller, ship's propeller, propeller blade, ship's engine, calculation, sand foundry, copper alloy foundry (copper-aluminium), foundry models, propeller models, industrial project, engineering sciences, scientific heritage, industrial heritage, maritime heritage, Fonderies de l'Atlantic (Foundry Firm)

\section{AUTEUR}

\section{JEAN-LOUIS KEROUANTON}

Maître de conférences associé. Centre François Viète (membre titulaire) Épistémologie, histoire des sciences et des techniques (EA 1161), Université de Nantes. jean-louis.kerouanton@univnantes.fr 